\title{
Gravel beach profile response allowing for bimodal sea states
}

Andrea Polidoro BEng (Hons), MEng

Engineer, Coastal Structures, HR Wallingford Ltd, Wallingford, UK (corresponding author: a.polidoro@hrwallingford.com) (Orcid:0000-0002-3044-0360)

Tim Pullen BEng (Hons), MEng, PhD

Principal Engineer, Coastal Structures, HR Wallingford Ltd, Wallingford, UK Jack Eade BEng, MEng

Coastal Process Scientist, Channel Coastal Observatory,

National Oceanography Centre, Southampton, UK
Travis Mason $\mathrm{PhD}$

Director, Channel Coastal Observatory, National Oceanography Centre, Southampton, UK

Belen Blanco PhD

Principal Scientist, Coasts \& Estuaries, HR Wallingford Ltd, Wallingford, UK

David Wyncoll PhD

Senior Scientist, Flood Management, HR Wallingford Ltd, Wallingford, UK

The south coast of the UK is identified as a location where significant wave swell components are present within the regional wave climate. During the winters of 2006 and 2014, several sites along the south coast of the UK were subject to significant damages where flood events were recorded. These sea states were characterised by having a double-peaked wave spectra, observing a connection between wave spectrum shape and beach response. A twodimensional (2D) physical model study was carried out to investigate the effect of gravel beach profile response under wave spectra characterised by swell-wave and wind-wave periods in various combinations. The physical model results showed the effect of bimodal wave spectrum on beach crest erosion and were compared with the parametric model Shingle and the numerical model XBeach-G. Based on this 2D physical model study, a new parametric model, Shingle-B, was derived and an online tool developed and made available on the website for the National Network of Regional Coastal Monitoring Programmes of England. This new tool has been validated at two sites in the south of England where field data of both waves and profiles were available.

\section{Notation}

$D_{x \%} \quad$ grain size that exceeds by size $x \%$ of the sediment distribution

$D_{50} \quad$ median grain size

$H_{m 0} \quad$ wind wave height

$H_{m 0 i} \quad$ significant incident spectral wave height

$L_{m 0} \quad$ mean wavelength

$L_{m-1,0} \quad$ deep water wave length

$m_{0} \quad$ total spectral energy

$Q_{\mathrm{p}} \quad$ peakedness parameter

$S(f) \quad$ incident spectral density

S\% $\quad$ swell percentage

$s, s_{0}, s_{m 0} \quad$ wave steepness

$T_{m 0,2} \quad$ mean spectral wave period defined using the zeroth and second moments of the frequency spectrum

$T_{m-1,0} \quad$ spectral wave period defined using the inverse and zeroth moments of the frequency spectrum

$T_{\mathrm{p}} \quad$ peak wave period

$y \quad$ wind wave spectral shape

$\beta_{i} \quad$ corresponding regression coefficients to be estimated when fitting

broadness parameter

narrowness parameter

breaker parameter

\section{Introduction}

Gravel beaches are a particular type of beach in which the sediments are solely composed of gravel sediment (2-64 mm, according to the Wentworth scale, Folk scheme (BGS, 1987)) according to López de San Román-Blanco et al. (2006). It is also common to find coarse-grained beaches that include both gravel and mixed (sand and gravel) sediments.

These beaches are common in mid- to high-latitude coasts (Carter and Orford, 1993; Hayes et al., 2009; Horn and Walton, 2007) but are also present on the shores of many parts of the world. Gravel beaches assume particular importance as defence systems along stretches of the heavily populated south coast of England where they are known as shingle beaches (Moses and Williams, 2008; Nicholls, 1990). Approximately one-third of the beaches in England and Wales are classified as coarse grained, especially along the south coast of England (López de San Román-Blanco, 2001). A gravel beach can be seen as a sum of different zones where the interaction of hydrodynamic processes and beach characteristics influence the final response of the beach. These zones are schematised in Figure 1. The most important zones for these beaches are the surf and swash zone. The surf zone is the zone of wave action extending from the water line out to the most seaward point of the zone where waves start breaking (breaker zone). In the surf zone, the sediments will be subject to a complex set of forces that are 


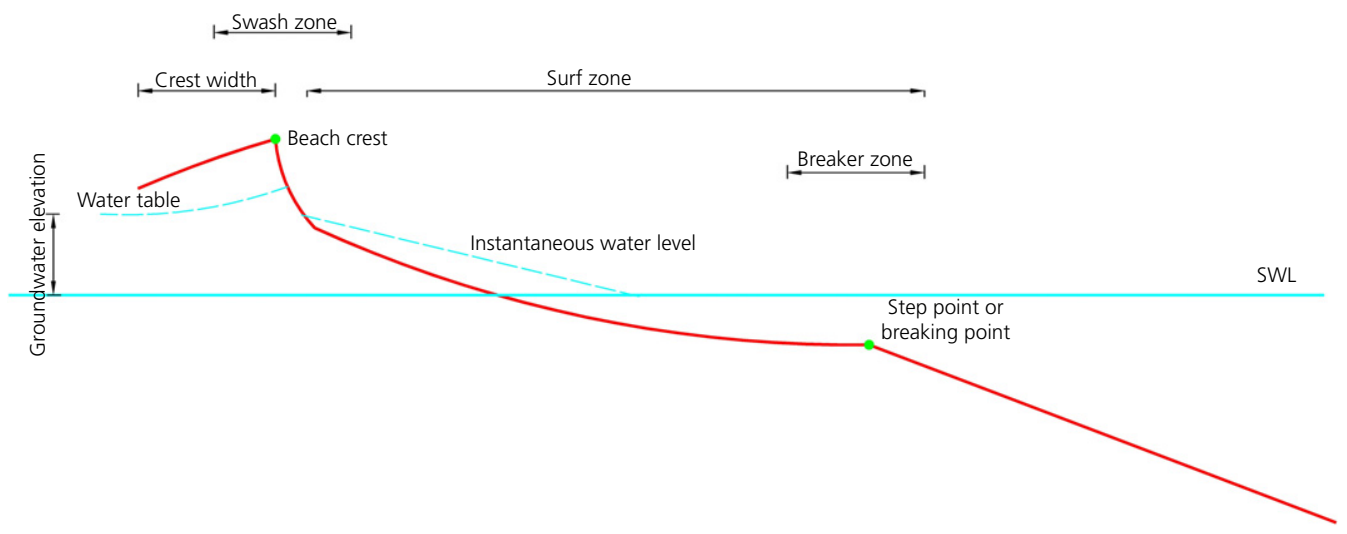

Figure 1. Schematisation of a general beach profile

produced due to bed friction and the impact of the breakers, which generates significant turbulence and sediment sorting. The surf zone is a very dynamic zone and the response of the beach profile is strongly linked to a change of the incident wave energy. The swash zone is the zone of wave action on the beach, extending from the limit of run-up to the limit of run-down. As discussed in more detail by Horn (2002), the interaction between wave motion and the beach groundwater table (see Figure 1) provides an important control on swash zone sediment transport.

Gravel beaches are an important form of natural coastal defence, protecting significant urban settlements as well as agricultural, recreational and environmental land areas against flooding and erosion (Powell, 1990; van Wellen et al., 2000). Their functions as coastal defences and natural habitats therefore compel coastal engineers to understand the processes occurring across the gravel beachface (Buscombe and Masselink, 2006). Beach behaviour is coupled with the incident wave conditions, hence the need for coastal engineers to study the approaching wave climate in order to have a reliable prediction of the beach response. In the south coast of England, it is common to have Atlantic swell waves penetrating into the English Channel (up to about Beachy Head), often leading to wave conditions with a broad, bimodal (combination of wind-wave and swell-wave components) or multi-modal spectrum (Bradbury et al., 2007). Along the south coast of England, a significant presence of bimodal sea states is recorded. The typical sites affected by bimodal conditions are Milford-on-Sea, Hayling Island, Rustington, Boscombe, Chesil, West Bay and Penzance (Bradbury et al., 2007).

The impact of wind waves on the coast in terms of overtopping, beach erosion, armour damage and so on are relatively well understood for many simple configurations (EurOtop, 2007; Powell, 1990; van der Meer, 1988). Conversely, swell waves, having longer periods than wind waves (Goda, 2010), are not generally considered in coastal structures design. However, it is possible that a combination of wind sea and swell waves represent a worst-case sea state for some aspects of beach design (Bradbury et al., 2006). Indeed, recent work carried out by Thompson et al. (2017) noted that bimodal sea states lead to greater overtopping and that the formulae available in the literature underestimate wave overtopping under bimodal wave conditions. An example of the effect of the bimodal sea states on coastlines was observed during the winters of 2006 and 2014, where several sites along the south coast of England were subjected to significant damage due to flooding events. The total economic damage for England during the winter period was estimated to be between $£ 1000$ million and $£ 1500$ million, including damage due to fluvial and groundwater flooding (Defra, 2016). A programme of near-shore wave measurement, wave hindcasting and beach response to extreme storm events in the English Channel found that bimodal (double-peaked) wave conditions produced more damage to the beaches than suggested by empirical models (based on statistical wave parameters) (Bradbury et al., 2002, 2004, 2007). In particular, the beach responses related to the measured wave data during these events suggested that the unexpected beach behaviour and breaching phenomena were linked to the spectral characteristics of the storm events (Bradbury et al., 2007). Interestingly, these sea states were characterised by having moderate rather than storm wave conditions, and their wave spectra presented a notable energy within low frequencies (Mason et al., 2008). Subsequent to these storm events, a correlation between bimodal wave spectra, beach response and breaching events was identified.

A two-dimensional (2D) physical model study carried out by Hawkes et al. (1998) confirmed the critical impact of longperiod energy influencing the beach response; however, in that study a predictive method was not developed. Hawkes et al. (1998) stated that, following the results of the study, the existing method of predicting beach response could be inadequate when bimodal conditions are present. 
Similar conclusions were confirmed by Bradbury et al. (2007), who observed that bimodal conditions significantly affect the beach profile performance, influencing the impact of wave runup, erosion and overwashing. They also emphasised the need to consider bimodal wave conditions as a design variable for some areas of the English Channel coast.

Unfortunately, little is still known about the effect of bimodal sea conditions on sea defences and beaches (Bradbury, 1998; Bradbury et al., 2007; Coates and Bona, 1997) and swell is rarely considered explicitly in the design or assessment of shoreline management operations. Indeed, as will be described in more detail in the following sections, the use of the existing prediction model for gravel beach profiles (Powell, 1990), known as Shingle, and the process-based XBeach-G (McCall et al., 2014) are not appropriate tools for bimodal conditions. This is because these prediction models are based on experiments carried out with simple unimodal sea states, neglecting the possibility of having the complex wave conditions that combine wind wave and swell, forming a bimodal spectrum. There was therefore an urgent need to better understand the effect of the interaction between wind waves and swell waves on the beach response and to developing understanding of the prediction of beach response under bimodal storm conditions.

The objective of this study was to develop a new parametric model for predicting beach profile response of shingle beaches under bimodal wave conditions in order to increase confidence in beach cross-section design. An empirical framework, based on extensive 2D physical model data and field work, was developed to examine the profile response of gravel beaches to bimodal wave spectra, characterised by swell-wave and windwave periods in various combinations. Based on this 2D physical model study, a new parametric model for predicting gravel beach profile response was derived. This model, called Shingle-B, is available online on the website for the National Network of Regional Coastal Monitoring Programmes of England (CCO, 2018a).

This paper discusses both the results of the physical model and the development of a parametric model, which represents an improvement over existing models for gravel coasts, subjected to bimodal wave conditions. Section 2 provides a more detailed description of bimodal sea states. The 2D physical model study and its results are discussed in Sections 3 and 4, respectively. The existing predictive methods for shingle beach morphological response are reviewed in Section 5 and applied to some of the physical model experiment results. The new parametric model, Shingle-B, is described in Section 6.

\section{Occurrence of bimodal sea states}

The presence of bimodal (double-peaked) wave spectra has been observed along several coasts of the globe - for example
Atlantic and Pacific Oceans (Garcia-Gabin, 2015), the west coast of New Zealand (Ewans et al., 2006) and the Gulf of Mexico and southern California (Mackay, 2016). In particular, on the south coast of England, Atlantic swell waves penetrate into the English Channel, often leading to wave conditions with a broad, bimodal or multi-modal (having several maxima) spectrum (Bradbury et al., 2007). The swell propagates up the English Channel reaching the coastline east of the Isle of Wight and can, occasionally extend the full length of the English Channel (Mason et al., 2008). Analysis of wave spectra from the National Network of Regional Coastal Monitoring Programmes' coastal wave network has identified that bimodal sea conditions occur on a regular basis (Mason et al., 2008). Typically, the highest presence of bimodal seas is associated with sites exposed to Atlantic swell - for example Porthleven in Cornwall. The occurrence of bimodal seas is seasonal, being more common during the winter months (December, January and February) and less common in the summer (June, July and August), as shown in Figure 2, where the average seasonal percentage of bimodal wave conditions recorded during the period from July 2003 to July 2016 is reported.

The effect of long-period waves on gravel beaches in the south coast of England was observed in the past. A typical example is Hurst Spit, which was breached several times during its life, and the spit was indeed breached several times between 1983 and 1984. The most severe damage, however, occurred on 16 and 17 December 1989, when southwesterly storms combined with a surge in excess of $1 \mathrm{~m}$ flattened an $800 \mathrm{~m}$ length of Hurst Spit (Bray and Hooke, 1998), as shown in Figure 3.

More recently, during the winter of 2013-2014, the south coast of England was exposed to an unusual and prolonged combination of severe storms. Many sites in central southern England experienced between five and seven storms during this period (October 2013 to February 2014). A number of storms exceeded the extreme wave conditions of one in ten years, or one in 50 year return periods, as shown in Figure 4, where the geographical occurrence/location of recorded return period exceedance between October 2013 and February 2014 is shown. Analysis of a 60-year hindcast wave model record (validated by offshore wave buoy measurements) by Masselink et al. (2016) suggests that the 2013-2014 winter was the most energetic since 1948. The storm sequences during the winter of 2013-2014 along the south coast of England had a considerable impact on many of the beaches. During these storms, Hurst Spit was subject to an unpredicted breaching (see Figure 5) and flooding and overwash events were observed in many other parts of the south coast of England.

The driving force behind this new research, however, has its roots in less stormy bimodal conditions. A sequence of 

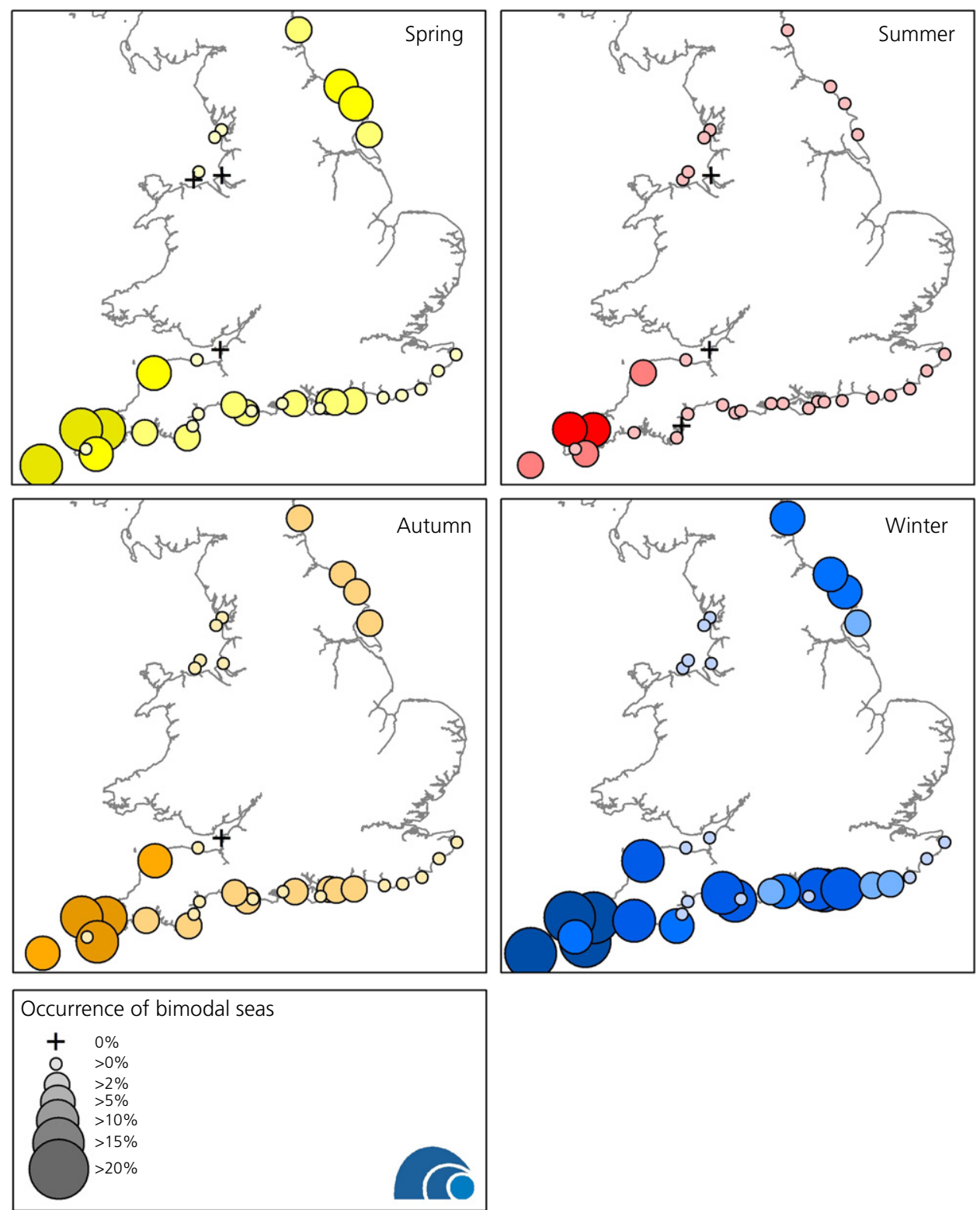

Figure 2. Seasonal occurrence of bimodal seas (extracted from CCO (2018b))

unexpected (not forecasted) coastal flooding events was observed at Seaton, Cornwall, in October 2006 and at Hayling Island on 3 November 2005. All these instances were recorded during periods of moderately, rather than stormy wind-wave conditions, but notable for the underlying presence of longperiod swell waves (Mason et al., 2008). Figure 6 shows Seaton during one of these unpredicted flooding events in October 2006. As it can be seen in the figure, the flood gate had remained open during the flooding event, highlighting the fact that the wind-wave forecast alone was unable to predict the potential for flooding.
In this study, the bimodal half-hourly spectra recorded at Chesil, Milford, Rustington and Hayling Island, from January 2005 to September 2015, were used to extract the occurrence of the swell percentage $(S \%)$ on the total wave energy spectrum. The spectra were obtained from the National Network of Regional Coastal Monitoring Programmes, and the results are shown in Figure 7, where it can be seen that for a bimodal wave spectrum, the swell component percentage ranged between 10 and $70 \%$. Most of the bimodal wave spectra present a swell component between 10 and $20 \%$, but cases of swell between 30 and $50 \%$ are common. In some cases, 


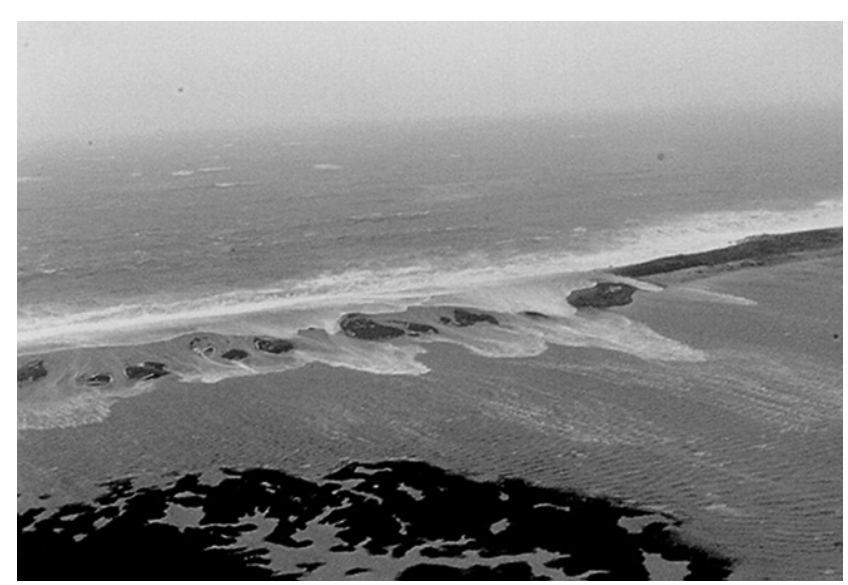

Figure 3. Hurst Spit, breached in 1989, at New Forest District Council (NFDC)

bimodal spectra with $70 \%$ of swell component have also been recorded. As discussed in more detail in the following section, the wave conditions tested in the $2 \mathrm{D}$ physical model consisted of $S \%$ ranging between 10 and $40 \%$, as these represent the vast majority of all the sea states analysed.

\section{Physical model study}

\subsection{Introduction}

A 2D physical model study was carried out using a $100 \mathrm{~m}$ long wave flume at HR Wallingford, with a wave paddle able to generate non-repeating random sea states to any required spectral form, including bimodal spectra. The model set-up is schematised in Figure 8 (model scale 1 in 25), where the location of the tested gravel beach and wave probes is shown. In order to reproduce the prototype beach response correctly, the model material had to be scaled according to the three main criteria described by Powell (1990). The methodology used to scale the gravel material is outlined here, with further detail given by Polidoro et al. (2015).

The three criteria defined by Powell (1990) needed to produce the correct beach response in a mobile bed physical model study are the permeability of the beach (Yalin, 1963) (controls the beach slope) the relative magnitudes of the onshore and offshore motion (Dean, 1973, 1985) (controls whether the beach erodes or accretes) and the threshold of sediment motion (Komar and Miller, 1973, 1975) (hence the onset of onshore-offshore transport).

A study of the sediment distributions for a typical range of gravel beaches along the south coast of England was carried out by Powell (1993). Based on Powell's work, a typical grading curve $\left(D_{50}=12.5 \mathrm{~mm}\right.$ and $\left.D_{10}=2.8 \mathrm{~mm}\right)$ was reproduced in this study by using four distinct mixes of crushed anthracite (specific gravity of $1400 \mathrm{~kg} / \mathrm{m}^{3}$ ). The anthracite used for the beach is supplied in six different grades, which were combined to achieve the model grading curve shown in Figure 9 (solid curve) plotted against the target grading curve (dashed curve). The use of anthracite to reproduce correctly the behaviour of a prototype gravel beach was confirmed by comparisons between the measured test profiles from the Großen Wellen Kanal (López de San Román-Blanco et al., 2006) with the profile predicted by Shingle (Powell, 1990). The good agreement between predicted and measured profiles generally indicated that the methodology previously adopted by Powell (1990) for smallscale testing of shingle beaches (use of anthracite) correctly describes the cross-shore profile response under normally incident wave conditions (Bradbury et al., 2002).

During this study, the initial beach slope was 1 in 8 (plane sloping beach) for all the test conditions, as shown in Figure 10. For each test, the post-storm beach profile was measured using a $2 \mathrm{D}$ bed profiler, which extracted the profile elevation every $20 \mathrm{~mm}$ along the $x$-axis. The bed profiler was mounted above the central section of the beach, enabling coverage of a $4 \mathrm{~m}$ (model) long profile across the mobile sediment. The touchsensitive probe had a proximity switch that allowed it to detect the bed with the minimum of contact pressure. The probe was stepped forward and lowered down on the bed; the encoder in the profiler then determined the bed height. This probe is particularly suitable for profiling both below and above the water surface. The bed profiler was used to monitor all tests with an accuracy of $\pm 1.0 \mathrm{~mm}$ vertically and horizontally (the prototype scale equivalent would be $25 \mathrm{~mm}$ accuracy or equivalent to one piece of large gravel).

For each wave condition, described in the following section, an in-line array of six wave gauges was used to measure both the incident wind and swell waves. Time histories recorded by each gauge in the array were analysed spectrally to give the following parameters: significant incident spectral wave height, $H_{m 0 i}$; peak wave period, $T_{\mathrm{p}}$; mean spectral wave period, $T_{m 0,2}$, defined using the zeroth and second moments of the frequency spectrum; the spectral wave period, $T_{m-1,0}$, defined using the inverse and zeroth moments of the frequency spectrum. The tests were carried out using a non-repeating sequence of duration equal to 3000 times the mean wind-wave period, $T_{m 0,2}$, of the target spectrum.

\subsection{Design wave conditions}

This section briefly outlines the waves used during testing, the shape of the spectrum, range of wave periods and how these are all related to the total spectral energy $\left(m_{0}\right)$. A more detailed discussion of the spectral shape is given in Polidoro et al. (2015).

The principal purpose of this study was to cover a large range of input conditions to examine the response of shingle beaches 


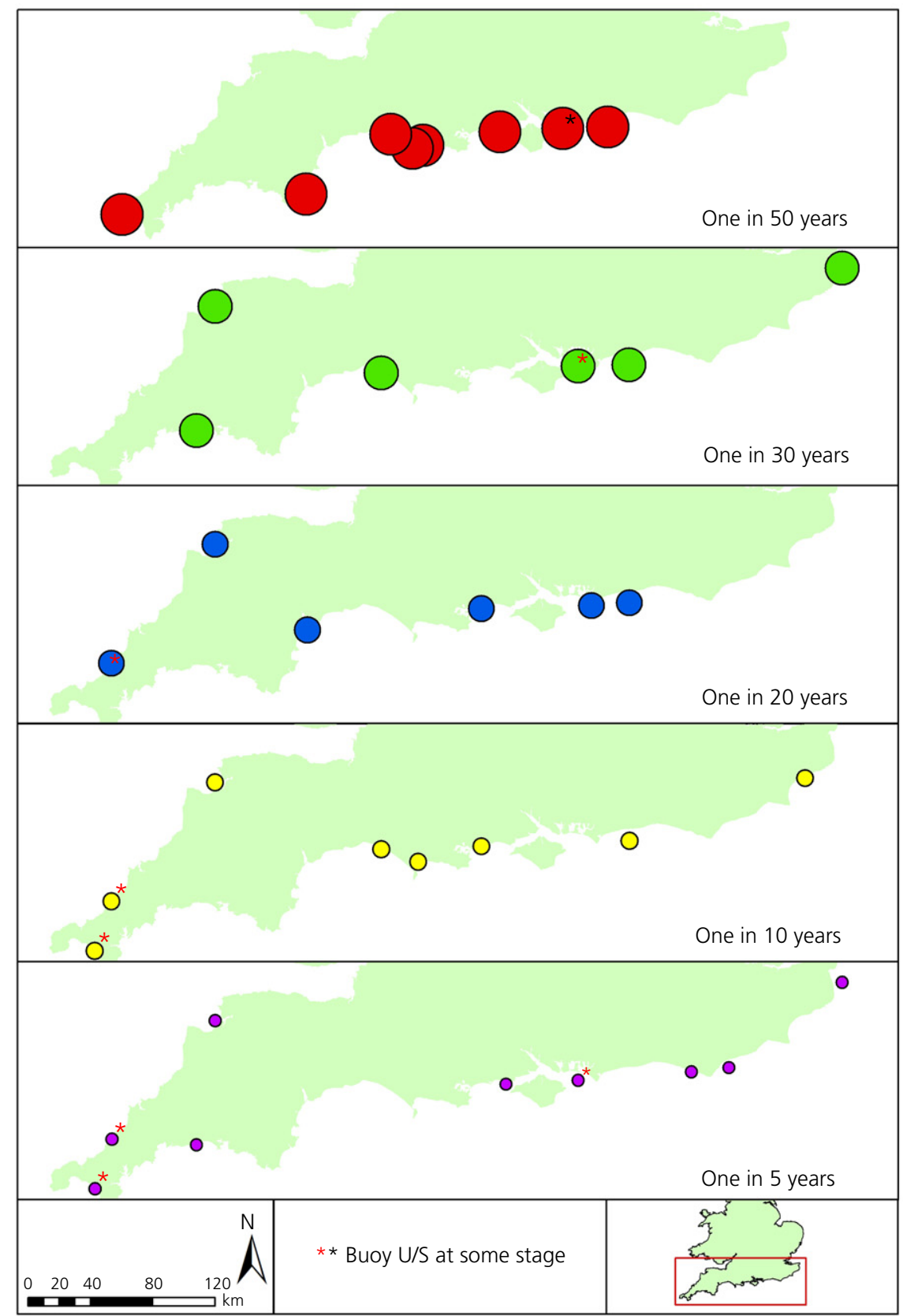

Figure 4. Distribution of storms exceeding the one in 5 year return period between October 2013 and February 2014 (adapted from Bradbury and Mason (2014))

under bimodal sea states, where design wave attack is assumed to be normal or near normal. The wave conditions were based broadly around a framework of measured conditions (wave height, wave steepness and wave periods) derived from wave buoys at Chesil, Milford-on-Sea and Hayling Island, as described in more detail by Bradbury et al. (2007) and Bradbury et al. (2009). Wave conditions were based broadly around prototype measurements covering a range of wave heights from 3.0 to $6.0 \mathrm{~m}$, swell periods from 15 to $25 \mathrm{~s}$ and wave steepness of $0.03,0.04$ and 0.05 . Once the wave heights were established, the wind-wave periods were changed to between 6 and $9 \mathrm{~s}$ to obtain the set wave steepness. Prototype wave conditions were defined at locations in 12-15 $\mathrm{m}$ water depth, therefore, wave measurements in the flume were made at correspondingly equivalent depths, as shown in Figure 8 (wave gauge buoy). 
Gravel beach profile response allowing

for bimodal sea states

Polidoro, Pullen, Eade et al.

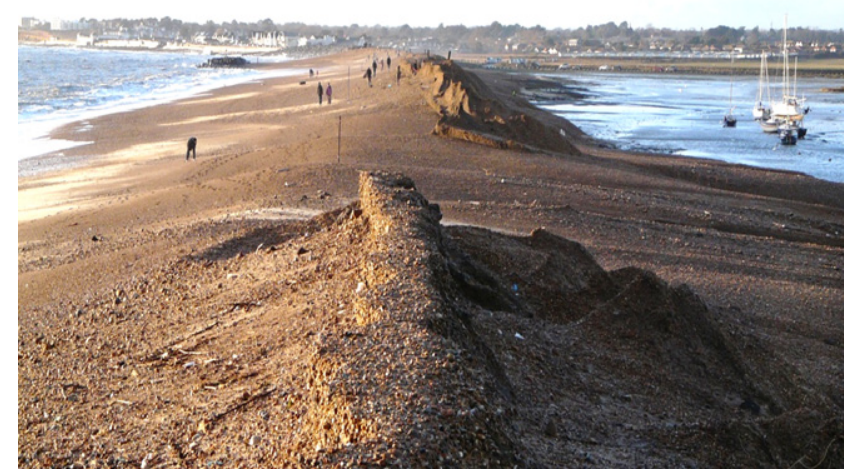

Figure 5. Hurst Spit, unpredictably breached in 2014 (courtesy Peter Ferguson at NFDC)

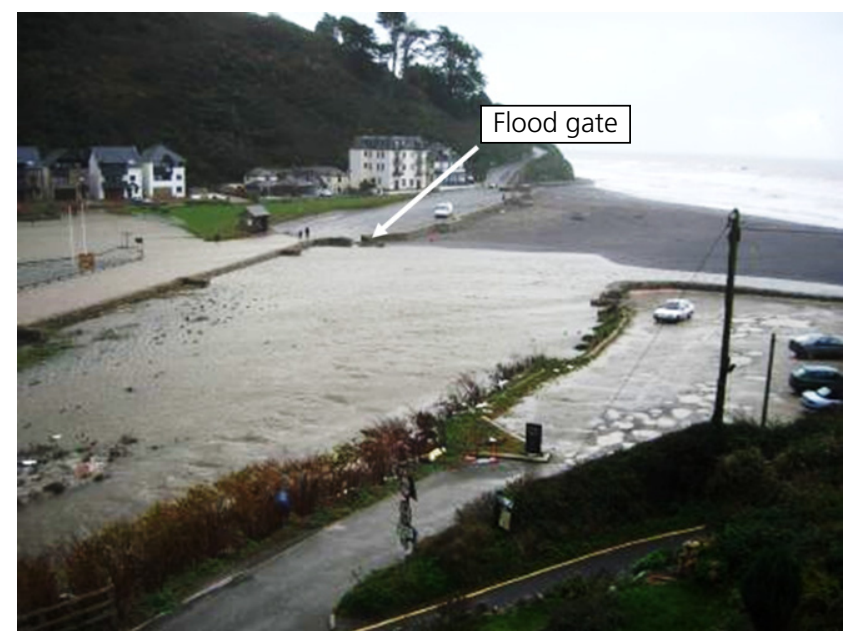

Figure 6. Seaton beach, Cornwall, 2006, the flood gate remained open during the flooding event (NFDC)

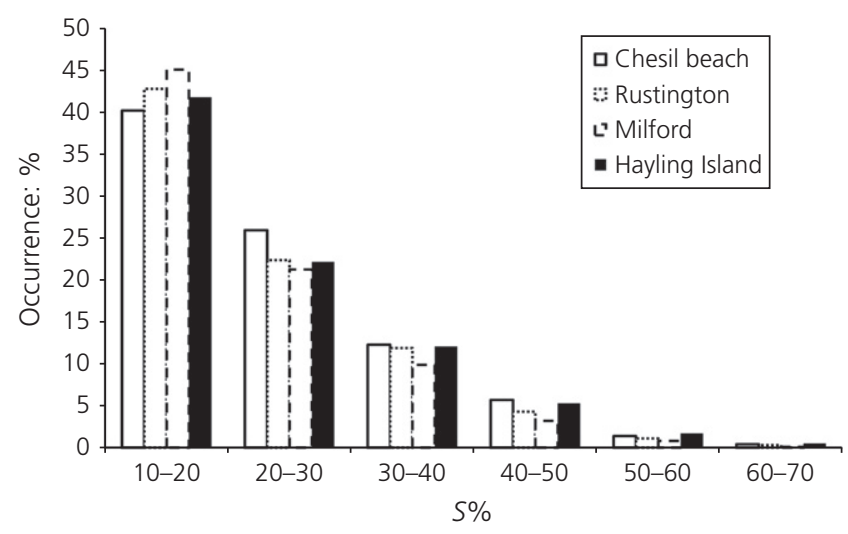

Figure 7. $5 \%$ occurrence for the bimodal wave spectra recorded during the period from 2005 to 2015
Each test was run with both a nominal wind wave and the associated idealised bimodal wave. The nominal wind wave was described by wind-wave spectral shape $(\gamma)$, wind-wave height $\left(H_{m 0}\right)$ and wind-wave period $\left(T_{\mathrm{p}}\right)$, as shown in Figure 11. The bimodal wave was described by a superposition of a wind wave and a swell wave, that together have the same total energy (area under the curve, $m_{0}$ ) as the nominal wind wave. The bimodal spectra is therefore predicted using the total $H_{m 0}$ (the sum of the energy in the spectrum), $T_{\text {pwind }}$, $T_{\text {pswell }}$ and the percentage of the swell component (Figure 11). The bimodal spectrum was modelled using a standard Jonswap spectrum with a peak enhancement factor of $\gamma=3 \cdot 3$ for the wind component. Analysis of swell waves generated off New Zealand showed that the swell spectra peaks were equivalent to the Jonswap spectra with $\gamma=8-9$ (Goda, 1985). This is because the swell waves have spectra confined in a narrow frequency range and thus have a peak much sharper than that of wind waves (Goda, 2010). For the swell component, even though swell waves tend to have a narrow and peaked spectrum, a Jonswap spectrum with enhancement factor of $\gamma=1.5$ was selected in order for the wave paddle generator to reproduce well-defined wave spectra for the low frequencies, without missing information when the wave energy was shifted from high to lower frequencies. Although the peak enhancement factor $(\gamma)$ is expected to have a certain degree of influence on the beach profile response, this has not been investigated in past research studies and it is outside the remit of this study.

To further investigate the variation of beach profile response and wave run-up with the spectral shape and the distribution of energy across the frequencies, each wave condition was run with the same spectral wave height $H_{m 0}$ (i.e. the same area under the spectrum) and successively subdivided to represent varying percentages of swell $(0,10,20,30$ and 40\%). This can be observed in Figure 12, where the total energy under the wave spectra is maintained, although distributed with different percentage swell components. The choice of $S \%$ was based on work carried out by Bradbury et al. (2007) and the additional analysis previously discussed and summarised in Figure 7.

\subsection{Test programme}

During these tests, different combinations of wave heights and wave periods were used in four steps of varying $S \%(10-40 \%)$ at a single water level on a 1 in 8 beach slope, with a difference in elevation between beach crest and beach toe of $17 \mathrm{~m}$. The tests were initially carried out with a single deep-water wave steepness $s_{m 0}=0.05$ and successively reduced to $s_{m 0}=0.04$ and $s_{m 0}=0.03$ in order to study the effect of wave steepness on the beach response. In addition, a fully developed swell sea state (unimodal wave spectra, 100\% swell component) was run with three different swell-wave periods to investigate the profile 


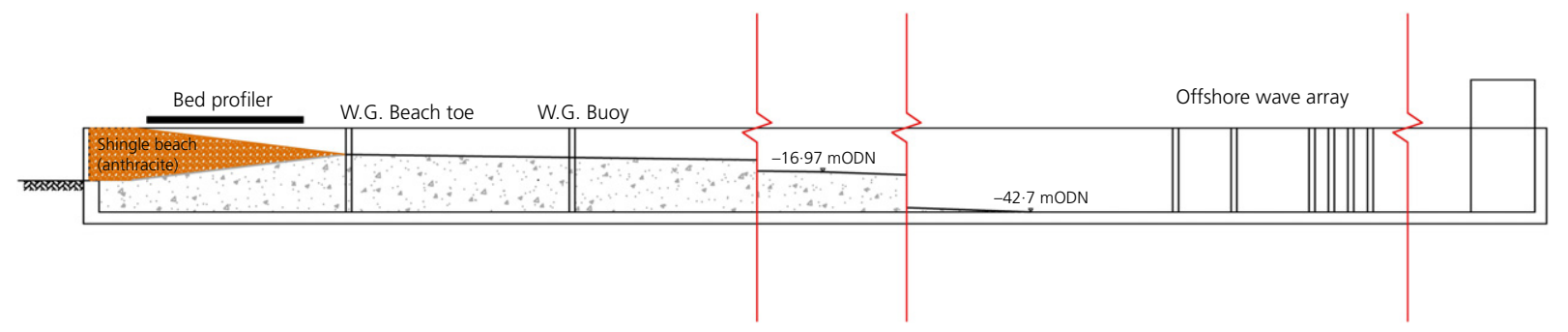

Figure 8. Model flume set-up. Note the flume is $100 \mathrm{~m}$ long. ODN, Ordnance Datum Newlyn; W.G., wave gauges

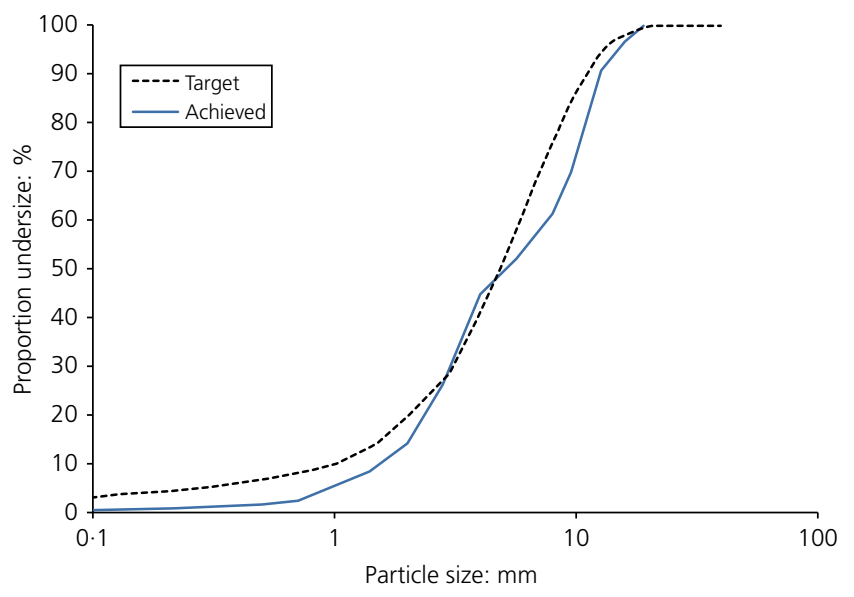

Figure 9. Target grading curve plotted against model grading curve of the anthracite used in the physical model tests

response under these conditions. A detailed description of each test series is given by Polidoro et al. (2015). Table 1 includes information on the order in which the test series were run plus brief details on the configuration of the shingle beach tested, the spectral wave heights and wave steepness that were run, the number of waves to reach the (dynamic) equilibrium profile and the number of tests.

\section{Physical model results}

\subsection{Introduction}

Each test was run initially for a duration of 1000, 2000 and 3000 waves; the duration being defined by the mean wave period $T_{m 0,2 w i n d}$. Beach profiles were measured following each sequence of 1000 waves. Although the initial intention was to continue each test until dynamic equilibrium was reached, the first test results showed that after 2000 waves the profile did not change significantly (see Figure 13) and that there was no discernible difference after 3000 waves. It was decided, therefore, to run for 3000 waves for the remaining tests, and only profile them once at the end of testing. This is in agreement with the results obtained by Powell (1990), who observed that approximately $80 \%$ of the total volumetric change occurred during the first 500 waves.

The representation of random sea waves can be considered as a stochastic process where the whole varies randomly with time (Goda, 2010). A given sea state, characterised by spectral energy, can be reproduced by an infinite number of time series having the same spectral energy (Goda, 2010). In order to investigate the effect of the time-series sequence on the final beach profile response, four different random time series (with the same wave spectrum and different random sequences) were generated. Results of the beach profiles under these four random time series are plotted in Figure 14. The final profiles showed that the crest position and the lower limit of the profile developments are relatively insensitive to the sequence of the time series. However, the beach profile within the surf zone is, as expected, slightly more sensitive to the sequence of the train of waves. This can be explained because within the surf zone waves start breaking and therefore non-linear responses influence the sediment transport. This part of the beach profile is very dynamic, changing almost wave by wave so that even the last sequence of waves affects the final profile. As a consequence, the final beach profile shows a small variability within the surf zone, possibly due to the effect of the final sequence of waves. Based on these observations, throughout this study it was decided to run different time series for each test condition. The ability to generate long non-repeating time series is of great importance when testing models that have a non-linear response, as in this case.

Almost 200 profiles were recorded and it is therefore not possible to present all of them in this section. Instead, results are presented where they assist understanding of the main outcomes or where it is necessary to illustrate trends or specific aspects of interest.

\subsection{Swell component effect on beach profile response}

An example of the effect of $S \%$ on the beach profile is plotted in Figure 15, where wave conditions with the same swell-wave 


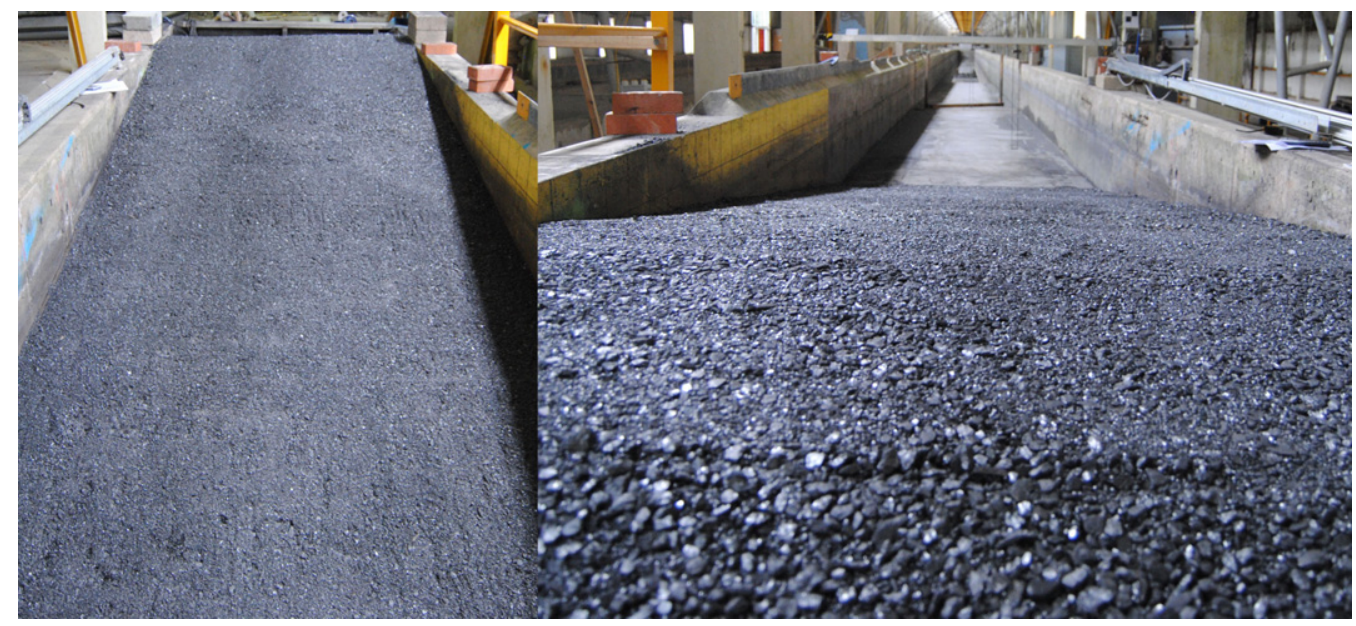

Figure 10. View of the tested plain beach

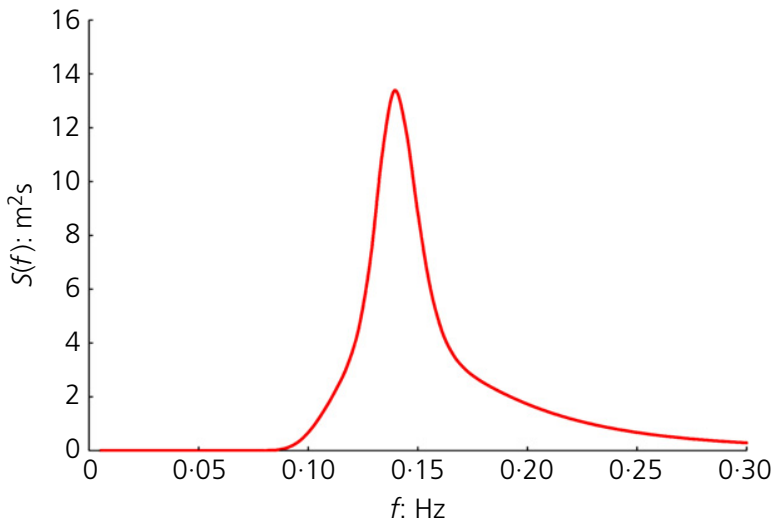

(a)

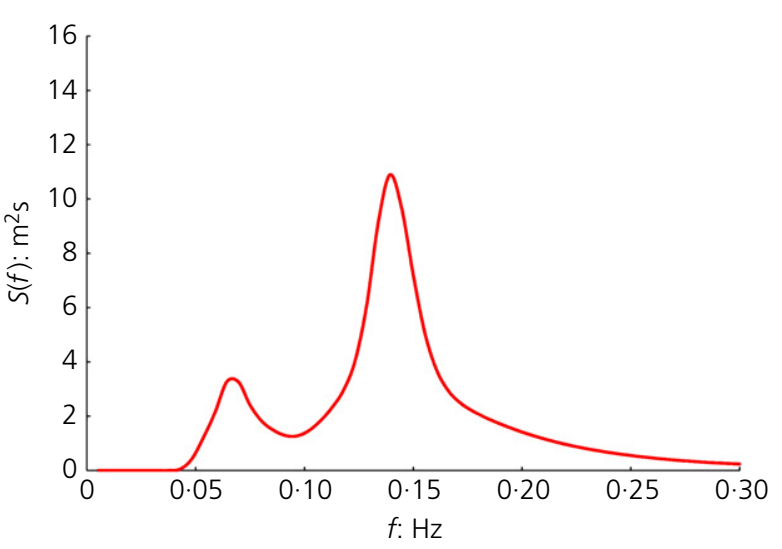

(b)

Figure 11. Wave spectra: (a) $H_{m 0}=4.0 \mathrm{~m}, T_{\mathrm{p} \text {, wind }}=7.0 \mathrm{~s}$ and $\gamma_{\text {wind }}=3.3 ;$ (b) $H_{m 0}=4.0 \mathrm{~m}, T_{\mathrm{p}, \text { wind }}=7.0 \mathrm{~s}, \gamma_{\text {wind }}=3.3, T_{\mathrm{p}, \text { swell }}=15.0 \mathrm{~s}$, $\gamma_{\text {swell }}=1 \cdot 3$, swell component $=20 \%$

period of $T_{\mathrm{p} \text {,swell }}=18 \mathrm{~s}$, same wave height of $H_{m 0}=3.0 \mathrm{~m}$, but different swell components are plotted. The influence of the swell component was observed mainly in the upper portion of the profile. The surf zone width increased significantly in response to an increase of $S \%$. This can be explained by the interaction of wind and swell waves on the final beach profile evolution. During the wave motion, long swell waves run up the beach and a significant volume of water infiltrates the beach. The amount of water that penetrates and is retained by the beach is also a function of the beach permeability - that is, the beach grain-size distribution (which was outside the remit of this study). This will raise the groundwater elevation, which is a function of both wave conditions and sediment sizes, and obviously the tidal level, which was not considered within these experiments. If the beach is almost saturated with water, during the backwash a thick layer of water within the surf zone

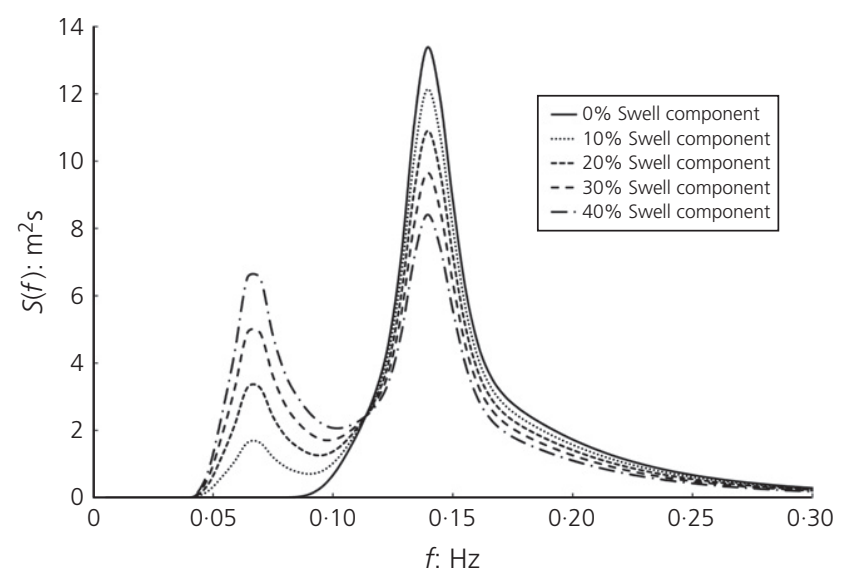

Figure 12. Wave spectra with different S\% 
Table 1. Test series programme

\begin{tabular}{llccclc|}
$\begin{array}{l}\text { Test } \\
\text { series }\end{array}$ & $\begin{array}{l}\text { Beach } \\
\text { configuration }\end{array}$ & Wave height: $\mathbf{m}$ & s: dimensionless & Number of waves & Purpose & $\begin{array}{c}\text { Number } \\
\text { of tests }\end{array}$ \\
\hline A & Slope 1 in 8 & $3.0-4 \cdot 5-5 \cdot 3-6 \cdot 0$ & 0.053 & $1000,2000,3000$ & Profile response to bimodal sea state & 104 \\
B & Slope 1 in 8 & 3.0 & 0.04 & 3000 & Profile response to bimodal sea state & 20 \\
C & Slope 1 in 8 & 3.0 & 0.03 & 3000 & Profile response to bimodal sea state & 20 \\
D & Slope 1 in 8 & 4.5 & 0.04 & 3000 & Profile response to bimodal sea state & 20 \\
E & Slope 1 in 8 & 3.0 & $0.003-0.004-0.006$ & 1000 & Profile response to bimodal sea state & 3 \\
\hline
\end{tabular}

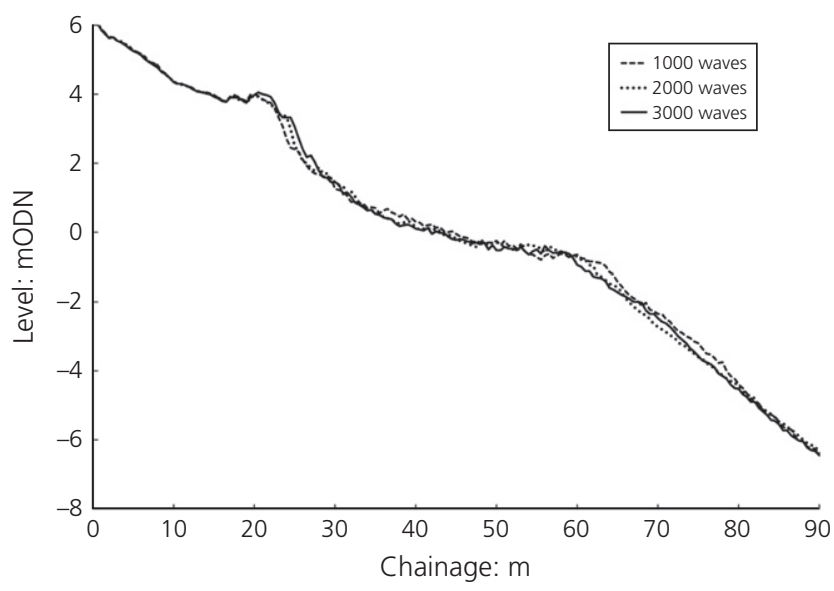

Figure 13. Profile development for a wave condition run for a duration of 1000,2000 and 3000 waves (based on $T_{m 0,2}$ ) in the physical model tests

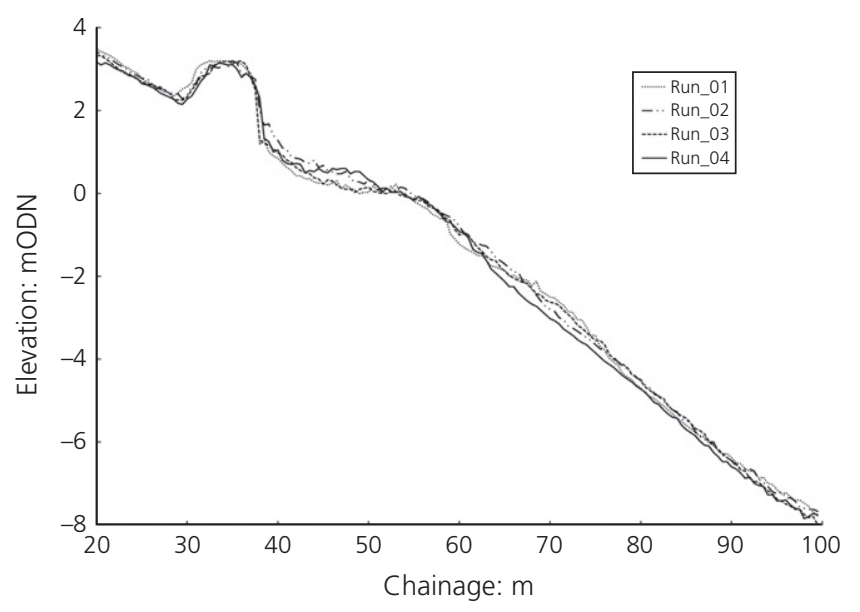

Figure 14. Effect of varying time-series sequence on beach profile response in the physical model tests

will be present (see Figure 16). The next incoming wave will surf on top of this water layer and, as the beach is now saturated, part of its energy cannot be dissipated within the beach. Most of the wave energy is, therefore, used to run on top of

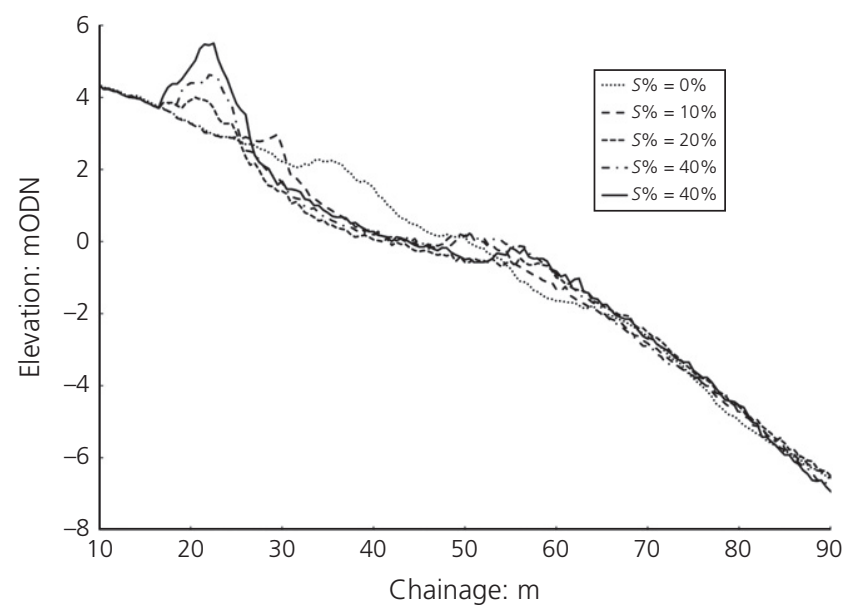

Figure 15. Effect of swell component percentage on shingle beach profiles $\left(H_{m 0}=3.0 \mathrm{~m}, T_{\mathrm{p} \text {, wind }}=7.18 \mathrm{~s}, T_{\mathrm{p}, \text { swell }}=18 \mathrm{~s}\right)$ in the physical model tests

the crest and push the beach crest landward. This phenomenon can be observed in Figure 16, where a breaking wave can be seen running on a beach already saturated with water.

Beach profile results (Figure 15) showed that the beach crest experienced a horizontal displacement in response to a shift of energy from high to low frequency. Interestingly, the results demonstrated that an increase of swell component higher than $20 \%$ (e.g. $30-40 \%$ ) had a more significant impact on the vertical displacement of the beach crest rather than the horizontal displacement. This suggests that an increased $S \%(>20 \%)$ will trigger an increase in crest elevation, rather than a horizontal displacement of the beach crest. Similar trends were also observed for the other swell-wave periods tested $(15,21$ and $25 \mathrm{~s}$ ).

\subsection{Swell-wave period effect on beach profile response}

The swell component tests demonstrated that the crest elevation was also affected by the swell-wave period. Accordingly, the effect of the swell-wave period $\left(T_{\mathrm{p}, \text { swell }}\right)$ on the beach profile was investigated by comparing profiles subject to the same wave height $\left(H_{m 0}=3.0 \mathrm{~m}\right)$, same wind-wave period 
Maritime Engineering

Volume 171 Issue MA4
Gravel beach profile response allowing

for bimodal sea states

Polidoro, Pullen, Eade et al.

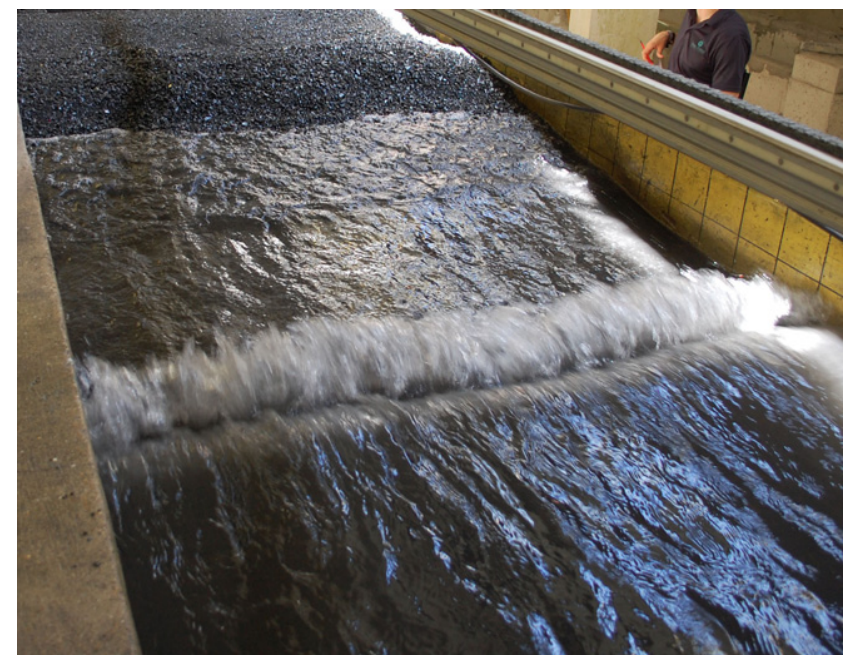

Figure 16. Beach saturated by swell waves and wind waves surfing on top of the sheet of water created by the previous swell wave

$\left(T_{\mathrm{p} \text {,wind }}=7 \cdot 18 \mathrm{~s}\right)$, same $S \%(10,20,30$ and 40$)$ but different swell periods $(15,18,21$ and $25 \mathrm{~s})$. An example of the effect of the swell periods on the beach profile is plotted in Figure 17 $\left(H_{m 0}=3.0 \mathrm{~m}, T_{\mathrm{p} \text {,wind }}=7.18 \mathrm{~s}\right.$ and $\left.S \%=30\right)$. Figure 17 shows that variations of swell-wave period had a substantial effect on the resulting profiles. The influence of the swell-wave period manifested itself mainly on the beach crest, with the crest position moving backwards and the crest elevation moving vertically in response to an increasing swell-wave period. Similarly, there is an increase in the crest elevation in response to an increasing swell-wave period as $S \%$ is increased. For the same

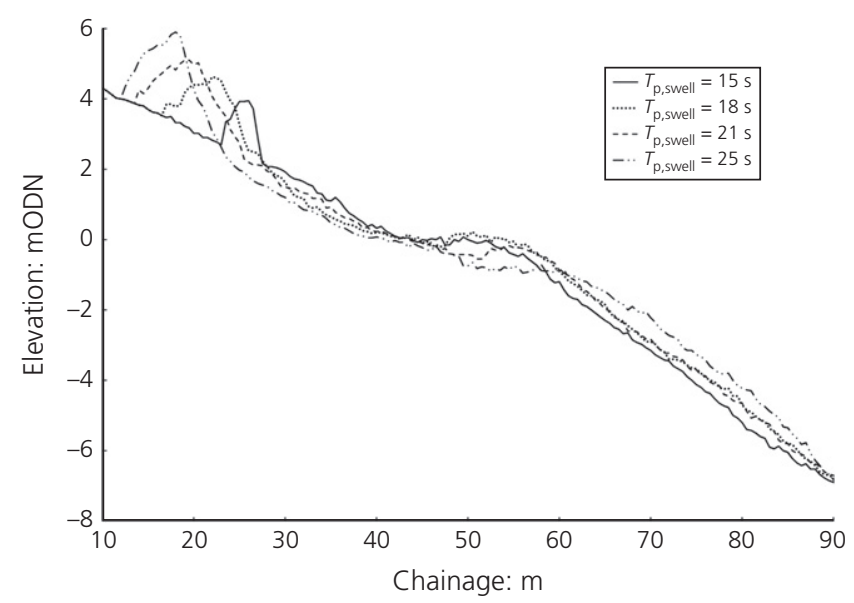

Figure 17. Effect of swell-wave period on the shingle beach profile $\left(H_{m 0}=3.0 \mathrm{~m}, T_{p, \text { wind }}=7.18 \mathrm{~s} ; \mathrm{S} \%=30 \%\right)$ swell-wave period, the higher the $S \%$ the higher the increase of the crest elevation.

It was also observed that the breaker zone increased in width in response to an increase in both the swell-wave period and $S \%$. The increase in the width of the breaker zone is a necessary response of the beach to dissipate increased incident wave energy but, during these wave conditions, the energy spectrum was kept constant $\left(H_{m 0}=3.0 \mathrm{~m}\right)$. This beach response may be attributed to the interaction within the surf zone between wind and swell waves, which significantly affects the run-up, rundown and groundwater elevation (see Figure 1), triggering a horizontal displacement (landward) of the beach crest. The effect of the groundwater elevation on the final beach profile was also discussed by Horn (2002) and Horn et al. (2006); it is a phenomenon extremely important for the beach evolution of coarse-grained beaches in particular, although it was not investigated during this study.

\subsection{Effect of wind-wave period on beach profile response}

The effect of the wind-wave period $\left(T_{\mathrm{p} \text {,wind }}\right)$ on the beach profile was investigated for both unimodal and bimodal spectra. The beach profiles, shown in Figure 18, were tested under the same unimodal wave spectra, with an equivalent wave height of $H_{m 0}=3.0 \mathrm{~m}$ and different wind-wave periods ( $T_{\mathrm{p} \text {,wind }}=7.18,8.26$ and $9.54 \mathrm{~s}$ ). The effect of variations in the wave period was observed more in the vertical dimension of the profile than in the horizontal displacements. Thus, as the wind-wave period increases, so does the beach crest elevation. This behaviour is in agreement with the results observed by Powell (1990), where only unimodal spectra were tested.

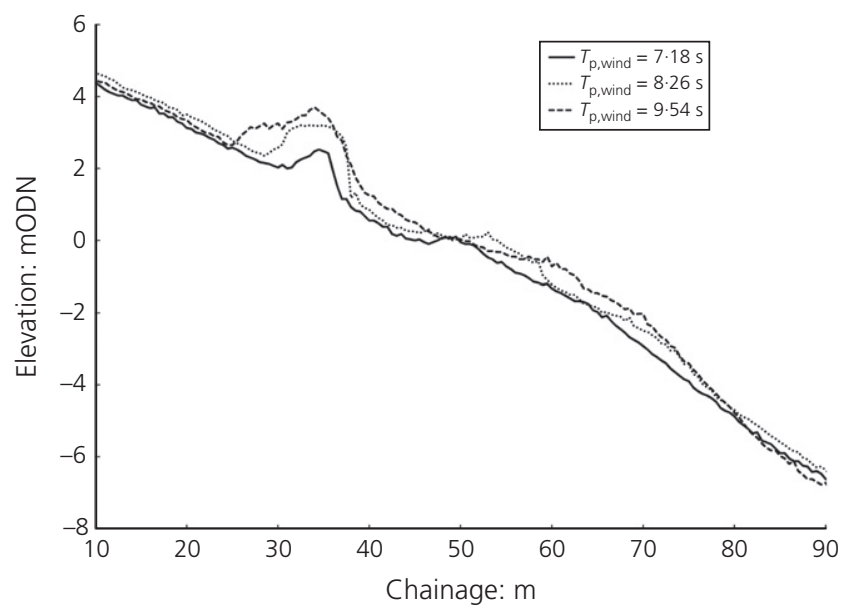

Figure 18. Effect of wind-wave period on the shingle beach profile under unimodal wave spectra with $H_{m 0}=3.0 \mathrm{~m}$ in the physical model tests 
Interestingly, under bimodal wave conditions, the increase of the crest elevation in response to an increasing wind-wave period is less significant than an increase of the wind-wave period under unimodal wave conditions, as shown in Figure 19. This plot shows four beach profiles subject to the same wave height, but under two different wind-wave periods. The profile response to unimodal wave conditions is represented with solid curves, while the profile response to bimodal wave conditions ( $20 \%$ swell component) are plotted with dashed curves. Clearly, the increment of the wind-wave period has a more significant impact on the unimodal condition than the bimodal one. This can be explained because, under bimodal wave conditions, the swell component and swell-wave period have a more significant impact than the wind-wave period on the amount of water infiltrating the beach (groundwater elevation) and therefore affecting the final profile.

\subsection{Wave height effect on beach profile response}

The influence of the wave height on the beach profile is shown in Figure 20. This figure shows the post-storm beach profiles exposed to two different incident wave heights $\left(H_{m 0}=3.0 \mathrm{~m}\right.$, dashed curve and $H_{m 0}=4.5 \mathrm{~m}$, solid curve) having the same wind-wave and swell-wave periods. As can be seen, the effect of the variation in the wave height triggers a horizontal displacement. The surf zone width increases significantly in response to an increasing wave height. This behaviour is in agreement with the results observed by Powell (1990). The increase in the width of the surf zone is necessary to dissipate increased incident wave energy, and this is realised by a lengthening of the surf zone rather than a change of the profile. This behaviour was observed for all the different tested wave heights.

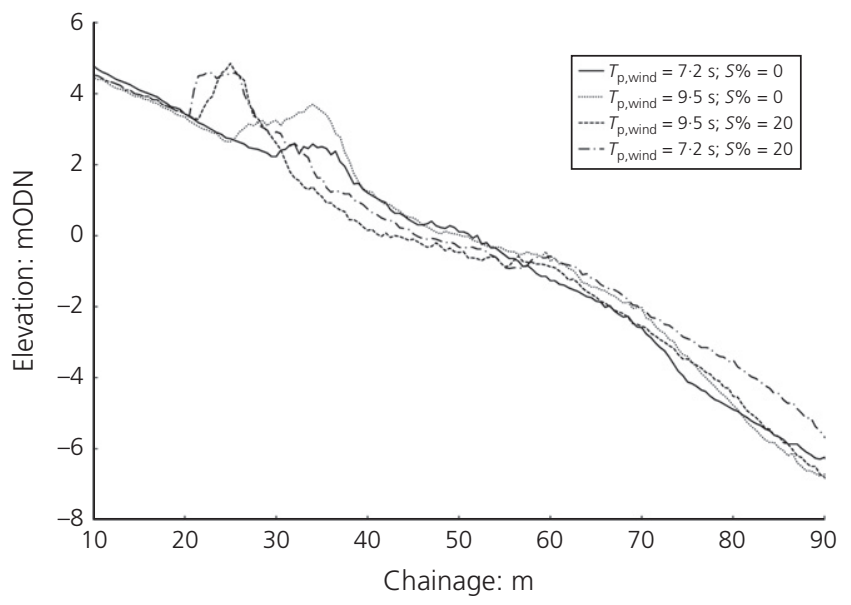

Figure 19. Effect of swell component on the influence of wind-wave period on the shingle beach profile in the physical model tests

\section{Comparison with existing predictive methods}

This section examines the main available methods used to predict gravel beach response under wave attack. The Shingle (Powell, 1990) and XBeach-G (McCall et al., 2014) prediction models are examined by comparing the predicted beach profile responses with the physical model test results for both a typical unimodal Jonswap wave spectrum (shown in Figure 21) and a bimodal wave spectrum (shown in Figures 22 and 23).

For a typical unimodal Jonswap wave spectrum $\left(H_{m 0}=3.0 \mathrm{~m}\right.$, $T_{\mathrm{p}, \text { wind }}=7 \cdot 18 \mathrm{~s}$ ), Shingle predicted profiles showing a very good correlation with the physical model results. The parametric

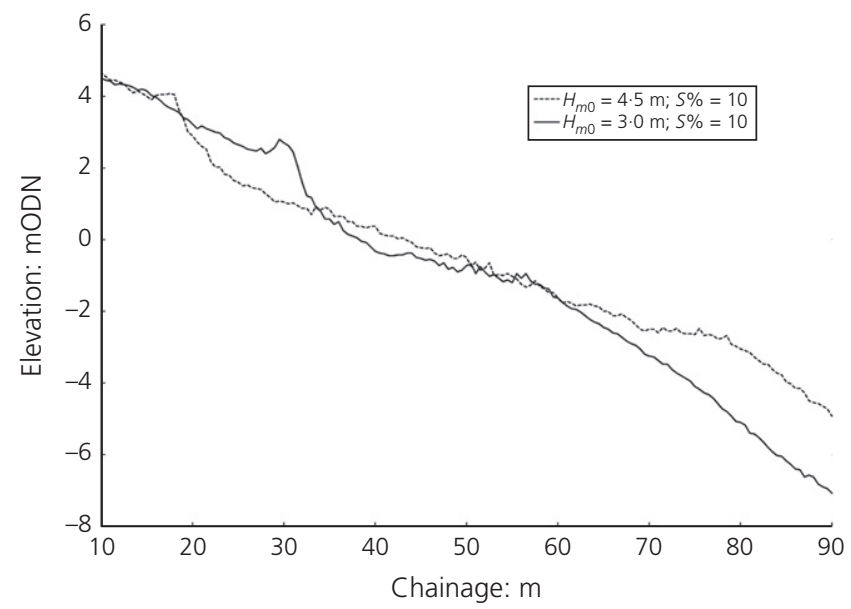

Figure 20. Effect of wave height on the shingle beach profile for bimodal (10\% swell component) wave conditions $\left(H_{m 0}=3.0 \mathrm{~m}\right.$, dashed curve; $H_{m 0}=4.5 \mathrm{~m}$, solid curve)

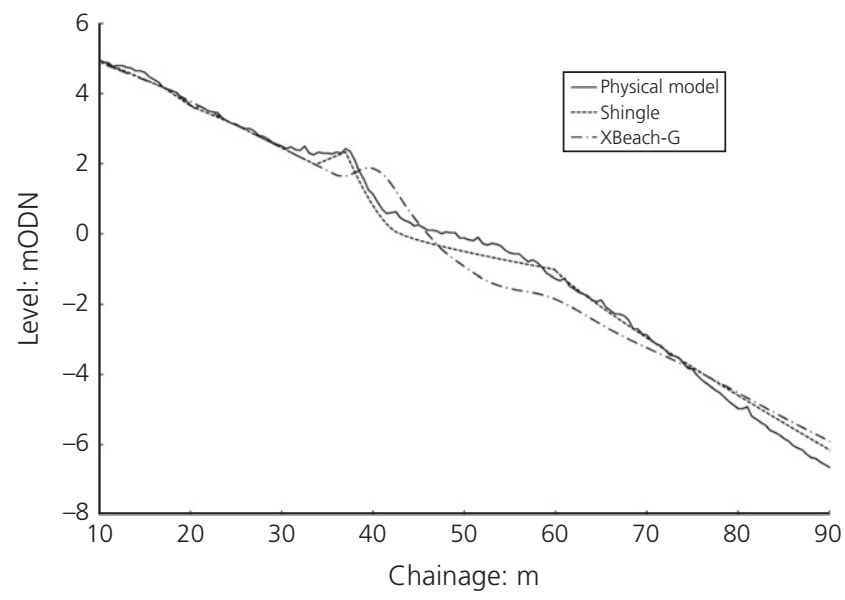

Figure 21. Beach profile comparison: XBeach-G, Shingle and physical model results for a unimodal wave spectra $\left(H_{m 0}=3.0 \mathrm{~m}\right.$, $T_{p \text {, wind }}=7.18 \mathrm{~s}, T_{\mathrm{p}, \text { swell }}=15 \mathrm{~s}, \mathrm{~S} \%=0 \%$ ) 


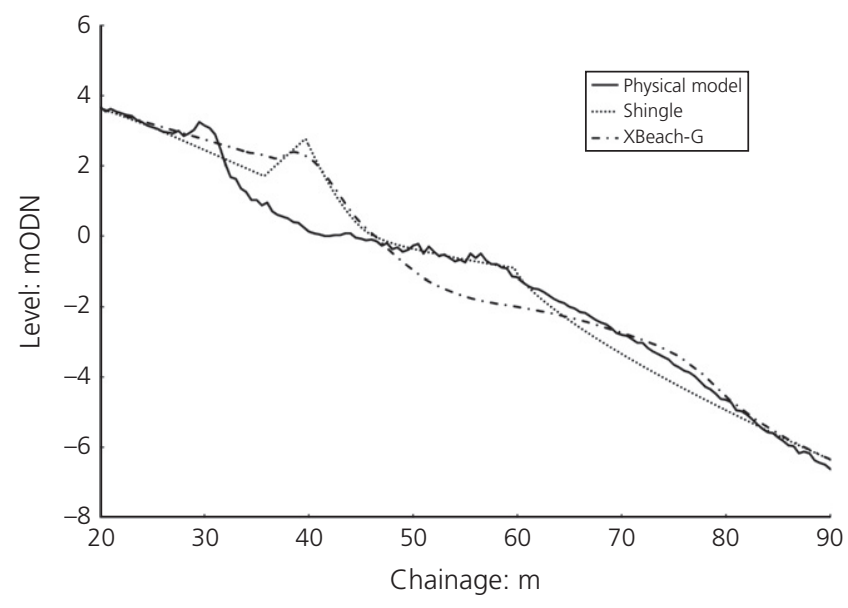

Figure 22. Beach profile comparison: XBeach-G, Shingle and physical model results for a bimodal wave spectra $\left(H_{m 0}=3.0 \mathrm{~m}\right.$, $T_{\mathrm{p}, \text { wind }}=7 \cdot 18 \mathrm{~s}, T_{\mathrm{p}, \text { swell }}=15 \mathrm{~s}$ and $\mathrm{S} \%=10 \%$ )

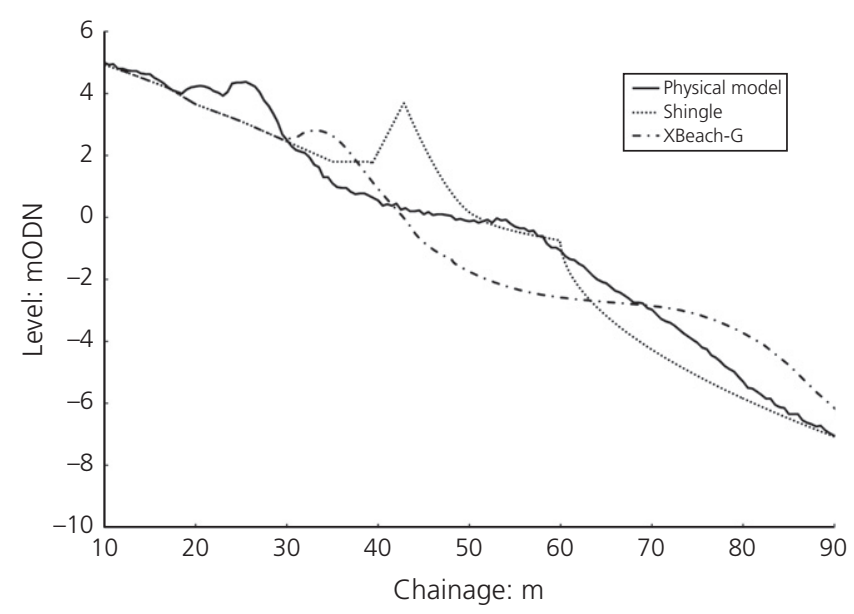

Figure 23. Beach profile comparison: XBeach-G, Shingle and physical model result for a bimodal wave spectra $\left(H_{m 0}=3.0 \mathrm{~m}\right.$, $T_{p, \text { wind }}=7 \cdot 18 \mathrm{~s}, T_{\mathrm{p}, \mathrm{swell}}=15 \mathrm{~s}$ and $S \%=40 \%$ )

model correctly predicted both the location of the beach crest, which tends to be the area of most interest to coastal engineers, and the location of the step (see Figure 21). Conversely, significant discrepancies were observed for the beach profiles predicted by XBeach-G, where the numerical model underestimated the horizontal displacement of the beach crest and predicted erosion where accretion was observed.

As previously described, in order to investigate the variation of beach profile with the spectral shape and the distribution of energy, the same spectral wave height $H_{m 0}$ (i.e. the same area under the spectrum) was run in four additional steps of varying $S \%(10-40 \%)$ at the same water level. Similarly, Shingle and XBeach-G models were examined by comparing the predicted beach profile responses with the physical model test for different bimodal wave spectra. Figures 22 and 23 show a comparisons of the predicted beach profiles and the post-physical model test results for bimodal wave conditions having, respectively, $10 \%$ and $40 \%$ of swell component.

It is worth mentioning that the Shingle model allows the user to input the wave height and the mean wave period $\left(T_{m 0,2}\right)$, but does not take into account the bimodality of the wave spectrum. During these tests, when varying $S \%(10-40 \%)$, the wave height remained constant and the spectral period $\left(T_{m-1,0}\right)$ increased. Therefore, when increasing $S \%$ during the tests, the input mean wave period $\left(T_{m 0,2}\right)$ in the Shingle model was replaced by the spectral period $\left(T_{m-1,0}\right)$. In Shingle, the effect of variations in the wave period triggers only the vertical displacement of the beach crest, neglecting its horizontal displacement. As a consequence of this deficiency, a significant discrepancy between the measured and predicted profiles for bimodal wave spectra was observed, as shown in Figures 22 and 23.

In contrast, in the XBeach-G model, the user is allowed to input a double-peaked wave spectrum, specifying the wave height and wave period for both wind and swell components. By comparing the measured and predicted profiles, a significant discrepancy was observed. The model does not predict the variation of the surf zone width in response to an increase of $S \%$ and, as a consequence, significantly underestimates the crest erosion (of the order of 10-20 m). The higher the $S \%$ within the incident wave condition, the higher the discrepancy observed (see Figures 22 and 23).

The laboratory experiments clearly demonstrated the effect of the double-peaked wave spectrum on the beach profile response, whereby a slight increase of low-frequency energy within the incident wave spectrum triggered a significant erosion of the beach crest. The comparison between predicted and measured beach profiles showed that the available prediction models (Shingle and XBeach-G) do not encompass the effect of the bimodality of the incident wave spectrum and, consequently, they significantly underestimate the crest erosion. Moreover, these models fail to predict the width of the beach crest correctly (see Figure 1), which, as discussed in Section 2, is an important feature for beach coastal management. These limitations clearly indicate that the current prediction models are not appropriate tools under bimodal sea states. Based on this 2D physical model study, a new parametric model for predicting beach profile response under bimodal sea states, Shingle-B, was derived, which is explained in the next section. 


\section{Shingle-B}

\subsection{Introduction}

The first part of this section describes how the new model schematises the beach profile and the relationship between profile parameters and bimodal wave variables. In the second part of this section, a validation against field data is presented.

\subsection{Profile schematisation}

The results observed during the physical model study showed how critical the crest erosion is during bimodal sea states. This critical aspect of the beach profile was also observed, as discussed in Section 2, over the course of the storm sequences

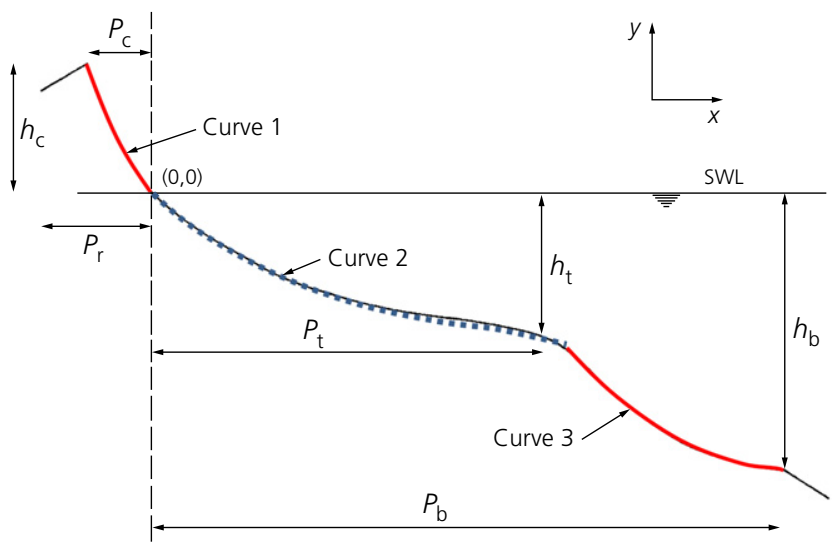

Figure 24. Schematised beach profile (Powell, 1990). $h_{\mathrm{b}}$, elevation of the beach base; $h_{\mathrm{c}}$ elevation of the beach crest; $h_{\mathrm{t}}$, elevation of the beach step; $P_{\mathrm{b}}$, position of the beach base; $P_{c}$, position of the beach crest; $P_{r}$, position of the maximum run-up; $P_{\mathrm{t}}$, position of the beach step during the winters of 2013-2014 along the south coast of England. For these reasons, the profile schematisation adopted for the present model is essentially a combination of the profile employed by Powell (1990) and the necessity to predict the post-storm crest width.

The model proposed by Powell (1990) employs three power-law curves to define the shingle beach profile, as shown in Figure 24: curve 1, beach crest and still water level (SWL) shoreline; curve 2, SWL shoreline and top edge of step; curve 3, top edge of step and lower limit of profile deformation.

As discussed in Section 1, for the present model there was the necessity to predict the landward displacement of sediment and the final crest width. In contrast to Shingle, the suggested beach profile schematisation adopts four curves, defined by their vertices as: curve 1, landward displacement and beach crest; curve 2, beach crest and start beachface point; curve 3, beachface point and top edge of step; curve 4, top edge of step and lower limit of profile deformation. The resulting schematisation is shown in Figure 25. Except for the crest width, the parameters were measured relative to the SWL and shoreline axes, as shown in Figure 26. The coordinates for the vertices of the curves are denoted by $x_{1}, y_{1}$ to $x_{5}, y_{5}$, as shown in Figure 25.

Many authors (Bruun, 1954; Dean, 1977; Hughes and Chiu, 1981; Keulegan and Krumbein, 1949; Powell, 1990; Van Hijum and Pilarczyk, 1982) have suggested that a hyperbolic curve of the form $y=A x^{n}$ provides the best description for a profile of a natural beach, where the coefficients $A$ and $n$ are functions of the beach characteristics and incident wave conditions, and $y$ and $x$ are the vertical and horizontal displacement.

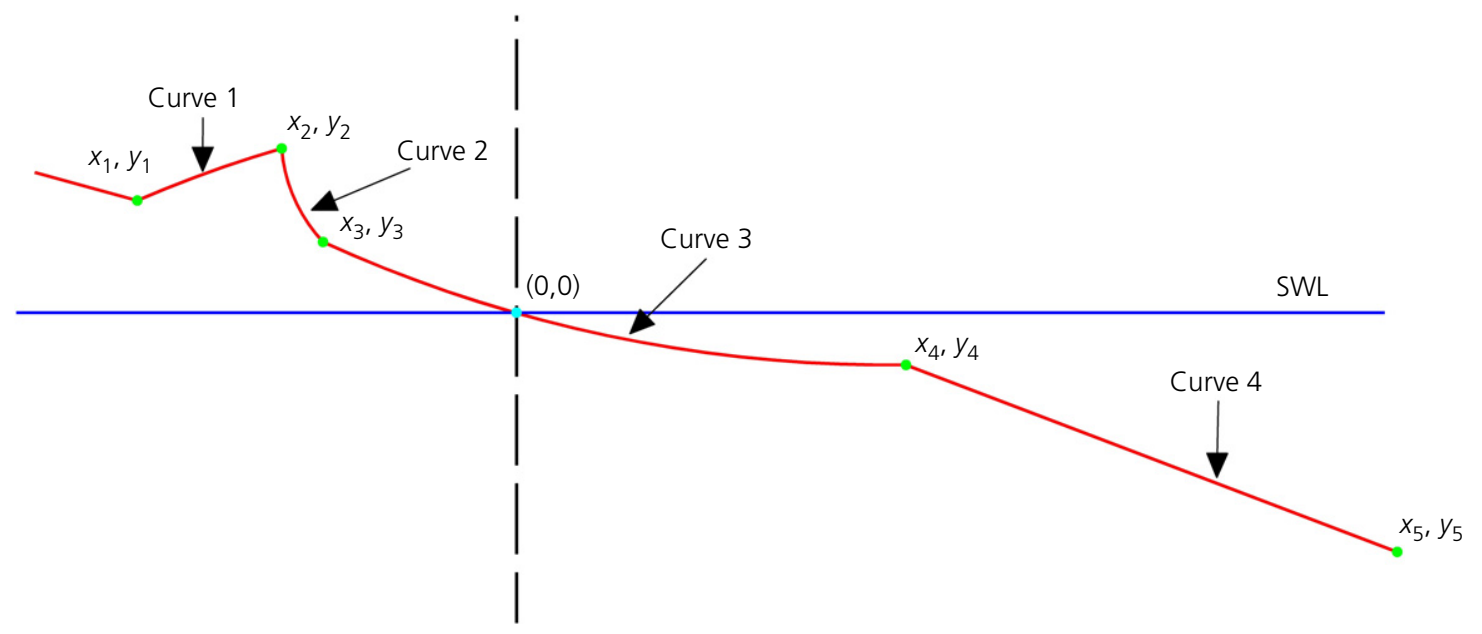

Figure 25. Schematised beach profile using four curves for Shingle-B model 


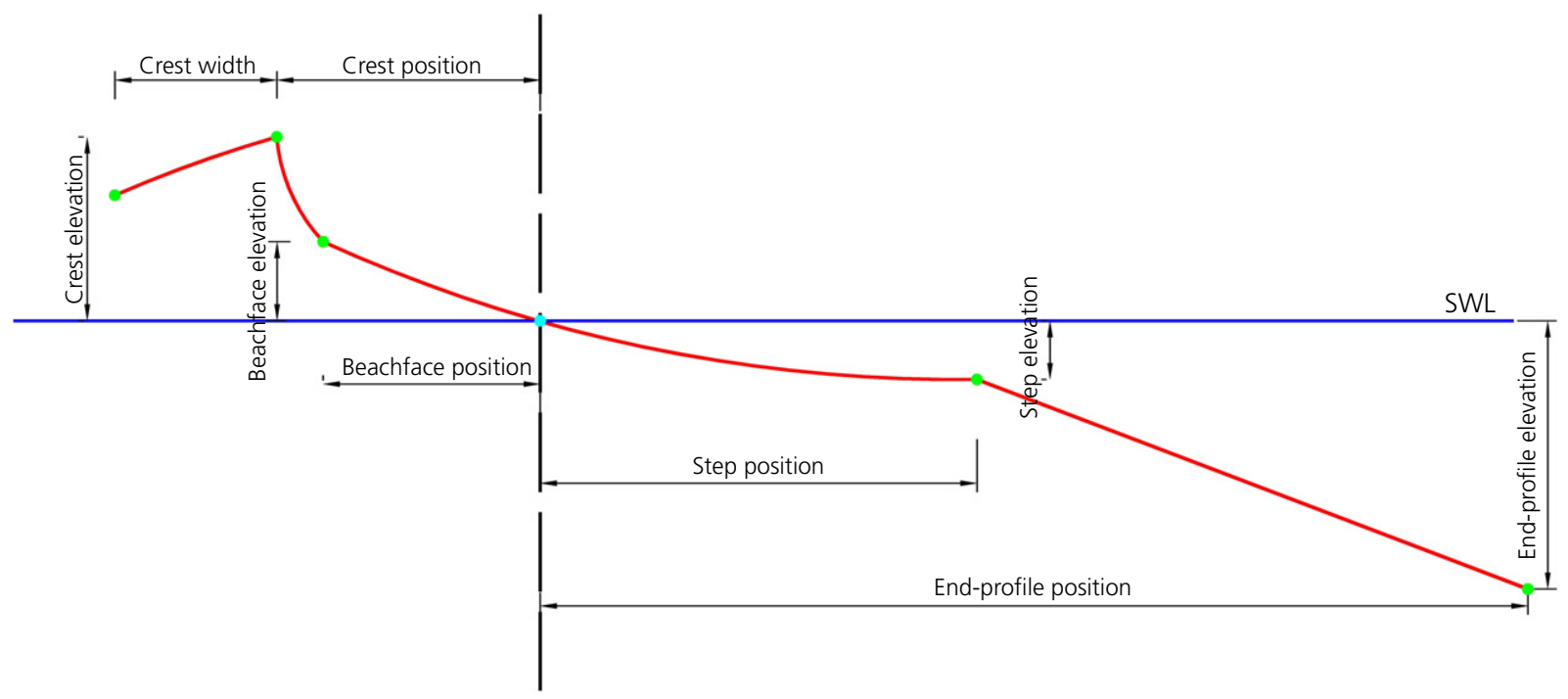

Figure 26. Schematised beach profile: parameters were characterised relative to the SWL and shoreline axes

During this analysis, the profile curves between the vertices assumed the same hyperbolic relationship. Once the beach profile was schematised, the functional relationship for each of the parameters listed above had to be determined. The relationship between the beach profile parameters and incident wave parameters is described in the following section.

\subsection{Beach profile parameter identification}

The physical model beach profiles were extracted using a bed profiler (see Section 3.1) that recorded chainage and level at any location along the beach. In order for functional relationships between beach profile and bimodal wave variables to be extrapolated, values (coordinates $x_{i}$ and $y_{i}$ ) of each of the beach parameters described above were extracted from the beach profiles recorded during the tests (see Figure 27). This was done by a combination of expert judgement and a leastsquares optimisation.

First, the crest position (point 2) and SWL intersection (bold cross, Figure 27) were manually selected for each of the observed profiles. The end profile location (point 5) was set to the end of the observed profile and an additional point (point 0 ) was temporarily assigned beyond the landward limit to the opposite end to cover the whole observed profile (see Figure 27).

A genetic algorithm is a method for solving both constrained and unconstrained non-linear optimisation problems by mirroring the natural selection process of biological evolution.

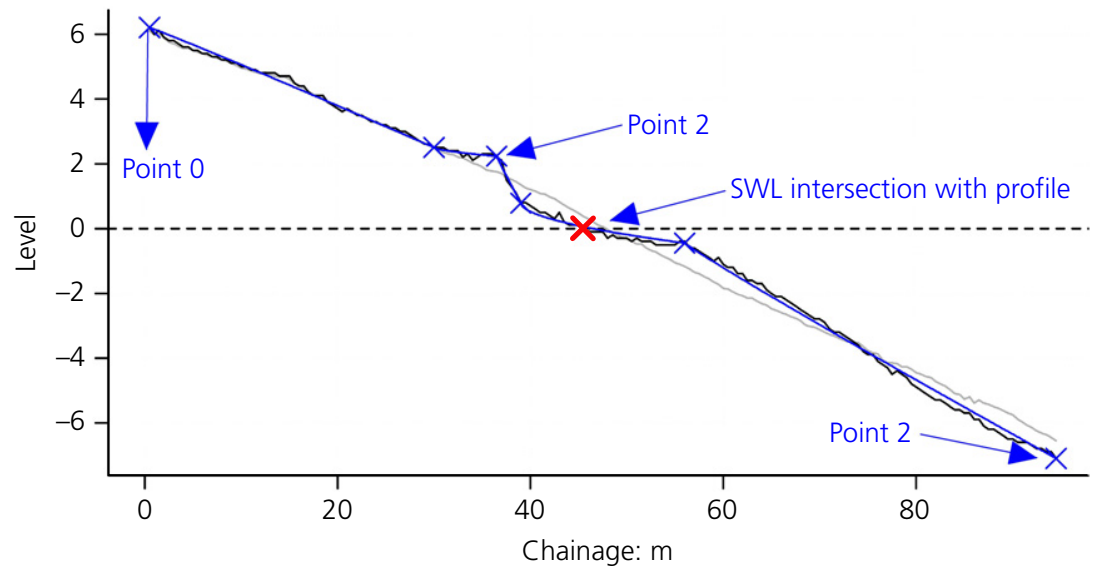

Figure 27. Beach parameter coordinates extracted from the physical model observed profile 
The algorithm is initialised with a population of multiple randomly generated potential solutions, each of which provides the $x$ and $y$ coordinates of the remaining beach parameters (i.e. for points 1, 3 and 4) in addition to a power $n_{i}$ for each of the six curves. This population is 'evolved' over a number of 'generations' using selection, cross-over and mutation processes that mirror natural selection. At each generation, the algorithm uses the 'fitness' of each solution to determine which 'parents' are used to create the 'children' of the next generation. Given a potential solution of beach parameter coordinates and power curves, the fitness is determined as the sum of the squared errors between the resulting fitted curves and the observed beach profile at every observed chainage, with lower errors preferred.

The resulting algorithm uses least-squares optimisation to find the best fitting set of hyperbolic curves for each observed profile.

This data set of beach parameter coordinates and hyperbolic curves then forms the training data for the subsequent regression analysis.

\subsection{Functional relationships between beach profile and bimodal wave variables}

The data set of the observed beach parameter values, shown in Figure 26, with the corresponding bimodal wave variables, was used to fit the equations for predicting each parameter, and hence the profile curve, as a function of bimodal wave variables. Multiple linear regression was used to describe each profile parameter by a parametric function of potentially multiple wave variables. This gives prediction equations of the general form

$$
y=\beta_{0}+\beta_{1} x_{1}+\beta_{2} x_{2}
$$

where $y$ is the parameter prediction, $x_{i}$ are covariates and $\beta_{i}$ are corresponding regression coefficients to be estimated when fitting. The covariates may potentially be any bimodal wave variable or transformations of them. Test series A-D, described in Table 1 (plane beach profile), were used to fit the model, ignoring the profiles at 1000 and 2000 waves, as discussed in Section 4.1.

For each profile parameter (e.g. crest elevation, crest position etc.), a model building exercise was undertaken to determine the exact form of the final regression equation by selecting which wave covariates to include. Finding this subset of covariates involves two opposing criteria: first, the regression model has to be as complete and realistic as possible - that is, including every covariate that is even remotely related to the dependent variable; and second, including as few variables as possible. This is because each irrelevant covariate decreases the precision of the estimated coefficients and predicted values. Moreover, the presence of extra variables increases the complexity of the final model. The goal of variable selection becomes a balance between simplicity (as fewer covariates as possible) and fit (as many covariates as needed).

On the basis of the discussion above, from a selection of potential covariates, a stepwise procedure was applied whereby the simplest model with no covariates was initially chosen then new terms were added or removed sequentially by selecting the term that minimises the Akaike information criterion (AIC) (Akaike, 1974; Burnham and Anderson, 2002). The AIC can be used to perform model comparisons, given a collection of models for the data. The AIC is an estimator of the relative quality of statistical models for a given set of data. Thus, it provides a means for model selection. The process systematically adds the most significant variable or removes the least significant variable during each step. This approach measures the goodness of fit of the equation but penalises the number of covariates to discourage overfitting, which would likely lead to poor estimates outside the fitted range (Burnham and Anderson, 2002). For each profile parameter, a set of equations was derived by the AIC method; the final one was manually selected to balance the goodness of fit with the model complexity, while also ensuring that the equation was physically meaningful (i.e. guaranteeing the physical phenomena observed and described in Section 4).

In Section 4, it was concluded that the most influential wave variables for the beach profile evolution were the spectral wave height $\left(H_{m 0}\right)$, wind-wave peak period $\left(T_{\mathrm{p} \text {,wind }}\right)$, swell-wave peak period $\left(T_{\mathrm{p} \text {,swell }}\right)$ and $S \%$. During the regression analysis, in addition to the main four variables, the following wave variables were also considered as covariates: spectral significant wave period $\left(T_{m-1,0}\right)$; mean wave period $\left(T_{m 0,2}\right)$; mean wavelength $\left(L_{m 0}\right)$; breaker parameter $\left(\xi_{0}\right)$; wave steepness $\left(s_{0}\right)$; and also three parameters related to the wave spectrum: broadness $(\varepsilon)$; narrowness $(v)$; peakedness $\left(Q_{\mathrm{p}}\right)$.

Ultimately, as a result of the stepwise regression analysis, the following four covariates were considered for inclusion in the regression equations: $H_{m 0}, S,(1-S) T_{\mathrm{p} \text {,wind }}$ and $S T_{\mathrm{p}, \text { swell }}$, where $S$ is $S \%$ as a decimal between 0 and 1 . The wind and swell peak periods were multiplied by factors involving the proportion of swell to ensure that the covariate has a valid value in all cases, including when the swell is $0 \%$ or $100 \%$ for which one of these periods is undefined.

The model selection process was conducted using $90 \%$ of the selected tests with a randomly selected $10 \%$ used for independent validation of the fitted models. An example of the analysis shows the results for the crest position and crest elevation in Figure 28. Ultimately, the selected regression equations were 

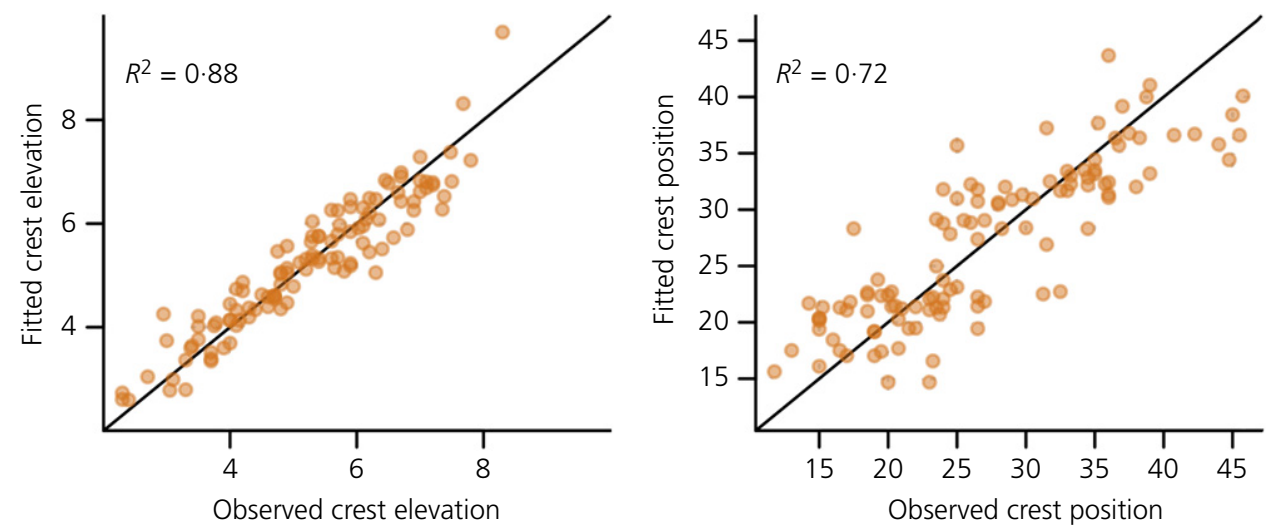

Figure 28. Fitted against observed values for validation of crest elevation and crest position

refitted using all of the selected tests. The final equations describing each parameter, and hence the profile curve, as a function of bimodal wave variables are reported in the Appendix. These equations are the basis of the online beach prediction tool Shingle-B.

\subsection{Model validation}

The final and perhaps most important stage was the validation of the Shingle-B model against field data. This, if successful, would confirm the correctness of the theory behind the beach physical modelling and generate confidence in the application of results from those models to natural situations. The following section focuses on some sites along the south coast of England and provides comparisons of profile response under known storm events. At each site, near-shore directional Datawell Waveriders, owned and maintained by the Regional Coastal Monitoring Programmes, were used to measure wave conditions throughout the survey period. The wave buoys form a national network of near-shore wave measurements and are moored in $\sim 12 \mathrm{~m}$ water depths, providing wave statistics on a half hourly basis.

\subsubsection{West Bay}

West Bay comprises East and West Beach. East Beach consists of a very fine shingle ridged beach with sand at the water's edge (see Figure 29). West Beach consists of a fine, smooth, pebbly beach, with shingle and sand at the water's edge.

A comparison of model results and post-storm beach profiles extracted at East Beach was carried out. Data obtained from the Channel Coastal Observatory website (CCO, 2018b) included simultaneous wave measurements and beach profiles. A single storm with a unimodal wave spectrum was recorded during January $2011\left(H_{m 0}=4.6 \mathrm{~m}, T_{\text {p,wind }}=10 \mathrm{~s}, S \%=0\right)$ and it was reproduced using Shingle-B, XBeach-G and Shingle (Powell, 1990). The prototype post-storm profile together with

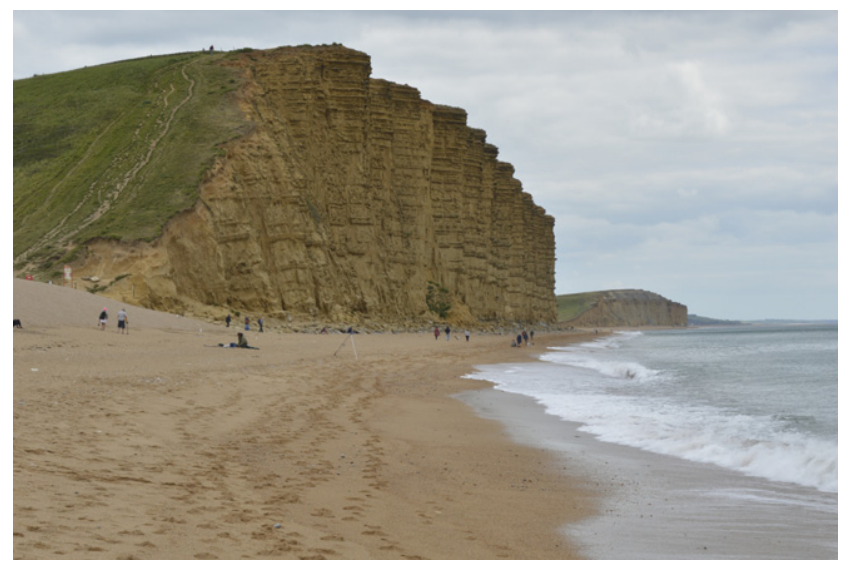

Figure 29. West Bay (East Beach)

the three predicted model profiles are plotted in Figure 30, where a reasonable agreement between measured prototype profile and Shingle-B predicted profile can be observed. As expected, under unimodal wave conditions, the Shingle (Powell, 1990) model also shows reasonable agreement with the prototype position of the beach crest and the rate of the crest erosion. Conversely, XBeach-G significantly underestimates the crest erosion.

\subsubsection{Rustington}

Rustington beach is a shingle beach with compact sand at low tide.

A comparison between model results and post-storm beach profiles extracted at Rustington was carried out. The data obtained from the CCO website (CCO, 2018b) included simultaneous wave measurements and beach profiles. A single storm with a bimodal wave spectrum was recorded during November 


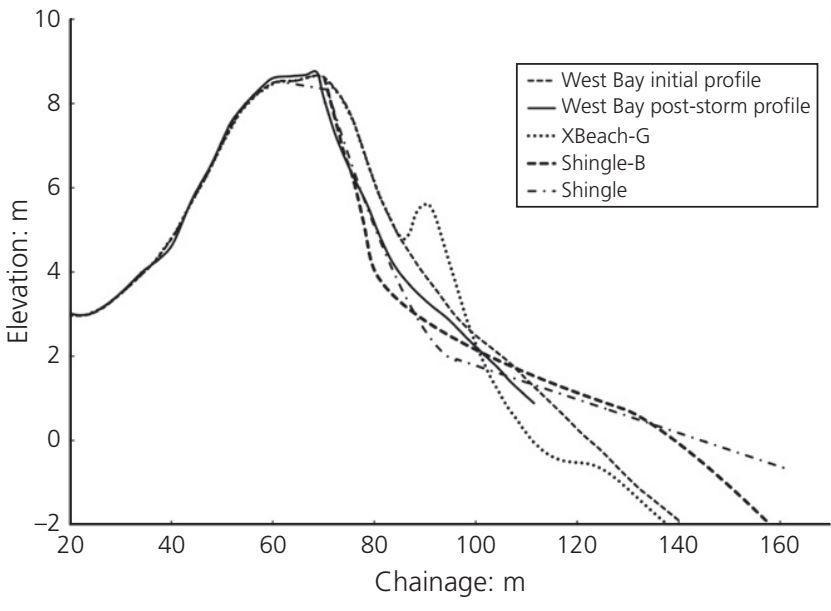

Figure 30. West Bay: post-storm profile against XBeach-G, Shingle (Powell, 1990) and Shingle-B predictions

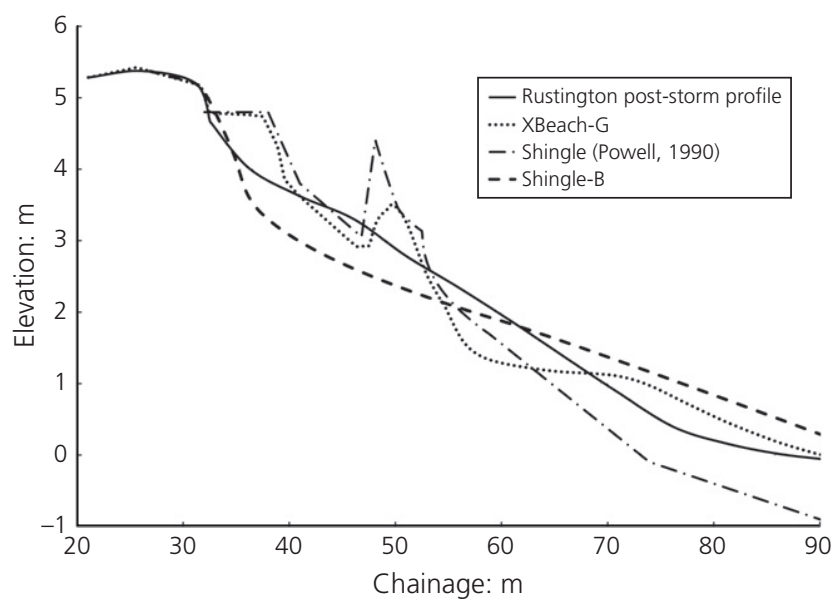

Figure 31. Rustington: post-storm profile against XBeach-G, Shingle (Powell, 1990) and Shingle-B predictions

$2005\left(H_{m 0}=3.5 \mathrm{~m}, T_{\mathrm{p}, \text { wind }}=7.0 \mathrm{~s}, T_{\mathrm{p}, \mathrm{swell}}=12 \mathrm{~s}, S \%=10\right)$ and it was reproduced by using Shingle-B, XBeach-G and Shingle (Powell, 1990). The prototype post-storm profile together with the three predicted model profiles are plotted in Figure 31, where Shingle-B model shows reasonable agreement with the prototype position of the beach crest and the rate of the crest erosion. Conversely, as expected under bimodal wave conditions, both Shingle (Powell, 1990) and XBeach-G significantly underestimated the horizontal displacement of the crest.

\section{Limitations of Shingle-B}

The study considered the effect of wave height $\left(H_{m 0}\right)$, windwave period $\left(T_{\mathrm{p} \text {,wind }}\right)$, swell-wave period $\left(T_{\mathrm{p}, \text { swell }}\right), S \%$ and the distribution of the spectral energy on the morphology of shingle beaches as a response to a storm condition.

As with all empirical methods, it is important to consider the range of applicability of the model in terms of the input parameters used for predictions. Whilst the fitted functions can provide estimates beyond the range of the data, there is little theoretical basis for their use in this regard. Although the range of the input data used to train the model could be tabulated for each of the specific input parameters, the practice of using the maximum and minimum values of each input parameter to define the range of applicability is questionable, particularly when parameters are correlated. There can be significant areas of the input parameter space unpopulated and hence predictions in these areas are generated by extrapolation not interpolation. This is illustrated in concept and for two variables only in Figure 32, where the parameter space covered by the maximum and minimum of two variables is given by the dashed rectangle; the area inside the dashed rectangle, although within the range of the variables, has no data to support the underlying predictions. This effect is significantly exacerbated the more dimensions are in the parameter space; in the current case four parameters (wave height $\left(H_{m 0}\right)$, windwave period $\left(T_{\mathrm{p} \text {,wind }}\right)$, swell-wave period $\left(T_{\mathrm{p} \text {,swell }}\right)$ and $\left.S \%\right)$.

The desire to extend the range of applicability of the model outside the range of the training data is perhaps understandable given the preponderance of existing similar structure types and the additional expense associated with constructing sitespecific physical models or more sophisticated numerical models. It is, however, appropriate to explicitly recognise and acknowledge that predictions resulting from extrapolation should be treated accordingly. Within the approach described here, specific attention has been directed towards the provision of guidance relating to the area of applicability of the model. The Mahalanobis distance (MD) (Mahalanobis, 1930) provides a quantifiable measure that can guide users on regions of valid application. The MD is a measure of a point from a multivariate distribution. Unlike the Euclidean distance, the MD accounts for correlated parameters, an important factor in the development of gravel beach profiles. In the online tool Shingle-B, the MD was used as a measure to come up with a range of applicability. This is represented in the tool as a coloured thumb, which is shown to indicate if the input wave conditions are within the limits of the training data set (green thumb), within input range but far from the training data (orange thumb) or outside the data range against which the model was trained (red thumb). This is also illustrated in Figure 32.

It is worth mentioning that the model Shingle-B is neither a breaching model nor does it deal with structures. Shingle-B only deals with the cross-shore profile; the longshore transport 


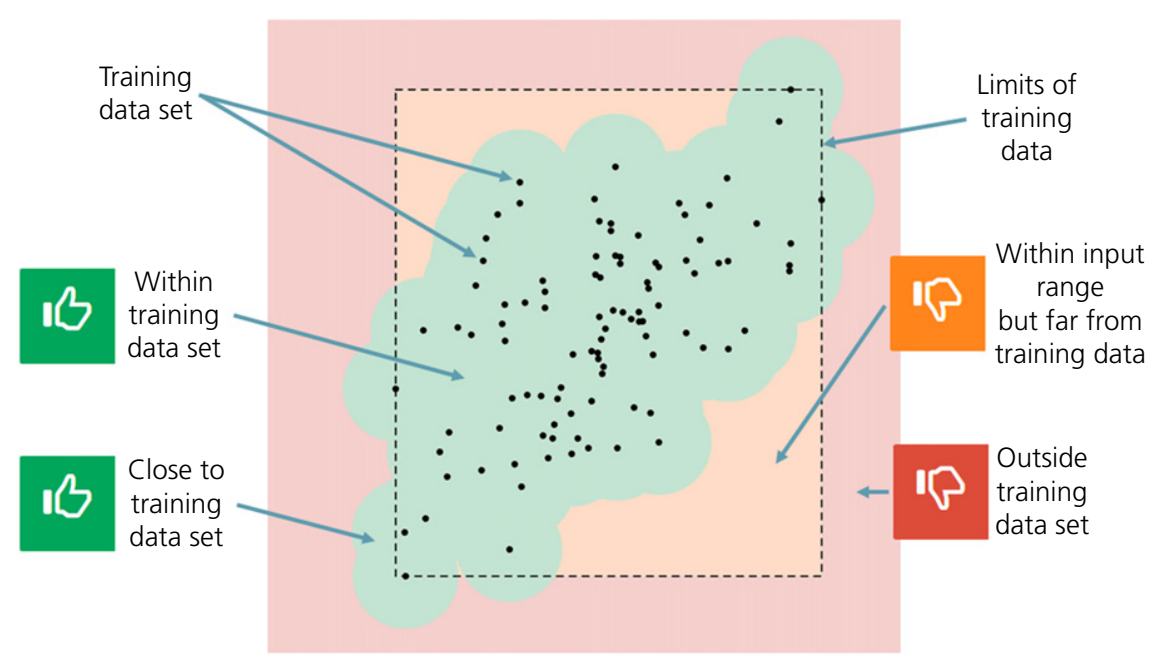

Figure 32. Input wave condition validation

not being considered. Formulations such as that proposed by van Wellen et al. (2000) should be used in order to deal with the longshore transport of coarse-grained beaches. Future physical modelling tests should include oblique wave attack and the inclusion of longshore sediment transport.

\subsection{Bathymetry}

While a fixed bathymetry seawards of the toe of the beach (typical of south coast beaches) was used, sites with extensive shallow foreshores will require some transformation of the wave conditions to determine more realistic input conditions. Such sites will likely have higher wave heights at the toe of the beach. Also, for other sites around the world, where more complicated bathymetry of the beach might be present, the user will be therefore required to adjust the Shingle-B input wave conditions to account for the difference in bathymetry.

\subsection{Diameter and grading of the beach material}

Sediment characteristics such as $D_{50}$ and grading width $\left(D_{85} / D_{15}\right)$ may affect the beach profile response. During this study, only one grading curve was used $\left(D_{50}=12.5 \mathrm{~mm}\right.$, $D_{10}=2.8 \mathrm{~mm}$ and $D_{85} / D_{15}=5 \cdot 0$ ) for the physical model tests; this was representative of south coast beaches, as discussed in Section 3. The sediment used within the physical modelling was scaled following Yalin (1963) in order to provide the most satisfactory reproduction of the prototype beach permeability, sediment mobility threshold and onshore-offshore transport characteristics (Powell, 1990). The scaling process results showed that the sediment model scale (anthracite), with a geometric scale of 1 in 25 , should be 1 in $2 \cdot 25$. The grading of the beach material, which affects its permeability, may influence crest elevation and crest regression; however, this effect was not explored during this study. The effect of the grading of the beach on the crest elevation was studied by Powell (1990), who observed decreasing crest levels for a narrower grading curve, although insufficient data were available to confirm this trend.

\subsection{Beach slope}

During this study, the initial beach slope in the physical model tests was fixed at 1 in 8 for each of the tests. Although the effect of the slope was not investigated, different wave conditions were repeated without reshaping the beach to the initial plane profile. The results of non-reshaped and reshaped profiles showed very good agreement, suggesting that the initial profile does not significantly affect the final profile.

Similar results were also discussed by Powell (1990) who concluded that whilst the initial beach slope does not necessarily affect the form of the active length of beach profile, it does affect its development.

\subsection{Underlying impermeable structure}

Physical model tests were run with a full thickness of beach material and the effect of impermeable membrane or sea walls was not considered during this study. The presence of an underlying impermeable layer within a shingle beach was investigated by Powell (1990). During that study (Powell, 1990) it was observed that if the ratio of effective beach thickness to median material size $\left(D_{50}\right)$ was less than 30 , the thickness of the beach was usually insufficient to retain material over the profile, and the beach structure was not stable.

\section{Conclusions}

An extensive series of physical model tests was undertaken to explore the behaviour and performance of gravel beaches under bimodal wave conditions. The tests considered the effect 
of the wave height, wind-wave period, swell-wave period and swell component percentage on the resultant beach profiles. The results from this study clearly demonstrated the effect of bimodal spectra on the evolution of a beach profile. The test results showed the critical effect of the bimodal sea state on both the vertical/horizontal displacement of the beach crest and the dynamic of the surf zone.

The model Shingle (Powell, 1990) and the numerical model XBeach-G (McCall et al., 2014) were found not to account for the influence of the spectral shape on the beach profile response and significantly underestimated the crest erosion under the bimodal wave conditions.

The physical model results allowed the development of a new parametric model, Shingle B, for predicting beach profile response on gravel beaches under bimodal sea states. Using the new parametric model, an online tool was developed and made available on the website for the National Network of Regional Coastal Monitoring Programmes of England (CCO, 2018a). The aim of Shingle-B is to offer an engineering tool to increase confidence in beach cross-section design under wave conditions characterised by double-peaked spectrum.

Initial validation of the model predictions against field data yielded encouraging results, suggesting that the parametric model provides a good representation of natural beaches and therefore represents an improvement over existing models for gravel coasts subjected to bimodal wave conditions. However, the present model would benefit from some additional comparisons and verification with field data.

\section{Acknowledgements}

This project was the brainchild of Professor Andy Bradbury, whose untimely death in August 2014, in the middle of the experiments, deprived the coastal engineering community of one of its foremost experts on gravel beaches. The authors are grateful to Keith Powell for guidance and supervision. The authors also wish to acknowledge support provided by the HR Wallingford Froude Modelling Hall staff. Shingle-B was funded by the Environment Agency as a flood and coastal erosion risk management grant-in-aid project, grant number LDW 4123.

\section{Appendix}

1. Crest width $=3 \cdot 92+0 \cdot 31 S T_{\text {p,swell }}$

$R^{2}=0 \cdot 24$
2. Crest position $=-8 \cdot 80+9 \cdot 10 H_{m 0}+0 \cdot 66 S T_{\mathrm{p}, \text { swell }}$

$R^{2}=0 \cdot 72$

3. Crest elevation $=-1.88+0.81 H_{m 0}$

$$
\begin{aligned}
& +0.31(1-S) T_{\mathrm{p}, \text { wind }} \\
& +0.37 S T_{\mathrm{p}, \text { swell }}
\end{aligned}
$$

$R^{2}=0 \cdot 88$

4. Beachface position $=-11.66+8.63 H_{m 0}$

$$
+0.52 S T_{\mathrm{p}, \mathrm{swell}}
$$

$R^{2}=0 \cdot 67$

5. Beachface elevation $=-0.65+0.71 H_{m 0}$

$$
+0 \cdot 12 S T_{\mathrm{p}, \text { swell }}
$$

$R^{2}=0 \cdot 56$

6. Step point position $=-17.76+8.67 H_{m 0}$ $+0.83 S T_{\mathrm{p}, \text { swell }}$

$R^{2}=0 \cdot 55$

7. Step point elevation $=-1 \cdot 19+0 \cdot 51 H_{m 0}$

$$
+0.06 S T_{\text {p,swell }}
$$

$R^{2}=0 \cdot 42$

8. End profile elevation $=12.23 \pm 1.50 H_{m 0}$

$R^{2}=0 \cdot 54$

\section{REFERENCES}

Akaike H (1974) A new look at the statistical model identification. IEEE Transactions on Automatic Control 19(6): 716-723. BGS (British Geological Survey) (1987) Sea Bed Sediments around the United Kingdom, 1:1,000,000 Map (North Sheet and South Sheet). BGS, Natural Environment Research Council, Nottingham, UK.

Bradbury A (1998) Response of Shingle Barrier Beaches to Extreme Hydrodynamic Conditions. PhD thesis, University of Southampton, Southampton, UK. 
Bradbury AP and Mason TE (2014) Review of South Coast Beach Response to Wave Conditions in the Winter of 2013-2014. Channel Coastal Observatory, Southampton, UK, Technical Report SR01.

Bradbury AP, Mason TE and Holt M (2006) Design and management implications for the use of modelled wave data in the southeast - a comparison between modelled and measured conditions. Proceedings of the DEFRA Conference of River and Coastal Engineers.

Bradbury AP, Mason TE and Holt MW (2004) Comparison of the performance of the Met Office UK - waters wave model with a network of shallow water moored buoy data, 2004. Proceedings of the 8th International Workshop on Wave Hindcasting and Forecasting, Hawaii.

Bradbury AP, Mason TE and Poate T (2007) Implications of the spectral shape of wave conditions for engineering design and coastal hazard assessment - evidence from the English Channel. Presented at the 10th International Workshop on Wave Hindcasting and Forecasting, Oahu, Hawaii.

Bradbury AP, Mason TE and Picksley D (2009) A performance based assessment of design tools and design conditions for a beach management scheme. Proceedings of the International Conference on Breakwaters, Structures and Coastlines, Edinburgh, UK. Thomas Telford, London, UK, pp. 338-351.

Bradbury AP, McFarland S, Horne J and Eastick C (2002) Development of a strategic coastal monitoring programme for southeast England. Proceeding of the International Coastal Engineering Conference, Cardiff, UK. ASCE, Reston, VA, USA.

Bray M and Hooke J (1998) Geomorphology and management of sites in Poole and Christchurch bays. In Coastal Defence and Earth Science Conservation (Hooke J (ed.)). The Geological Society, Bath, UK, pp. 233-266.

Bruun P (1954) Coast Erosion and the Development of Beach Profiles. U.S. Army Engineer Waterways Experiment Station, Vicksburg, MS, USA, Beach Erosion Board Technical Memorandum no. 44.

Burnham KP and Anderson DR (2002) Model Selection and Multimodel Inference: A Practical Information-Theoretic Approach, 2nd edn. Springer, New York, NY, USA.

Buscombe D and Masselink G (2006) Concepts in gravel beach dynamics. Earth-Science Reviews 79(1-2): 33-52.

Carter R and Orford J (1993) The morphodynamics of coarse clastic beaches and barriers: a short and long-term perspective. Journal of Coastal Research 15: 158-179.

CCO (Channel Coastal Observatory) (2018a) Shingle-B. CCO, Southampton, UK. See http://www.channelcoast.org/ccoresources/ shingleb/ (accessed 10/10/2018).

CCO (2018b) http://www.channelcoast.org/ (accessed 16/02/2011).

Coates TT and Bona PFD (1997) Recharged Beach Development, a Field Study at Highcliffe Beach, Dorset. HR Wallingford, Wallingford, UK, Technical Report SR 438 .

Dean RG (1973) Heuristic models of sand transport in the surf zone. Proceedings of the 1st Australian Conference on Engineering Dynamics in the Surf Zone, pp. 208-214.

Dean RG (1977) Equilibrium Beach Profiles: US Atlantic and Gulf Coasts. University of Delaware, Newark, DE, USA, Technical Report No 12.

Dean RG (1985) Physical modelling of littoral processes. In Physical Modelling in Coastal Engineering (Dalrymple RA (ed.)). Balkema, Rotterdam, the Netherlands, pp. 119-139.

Defra (Department for Environment, Food and Rural Affairs) (2016) The Costs and Impacts of the Winter 2013 to 2014 Floods. Defra, London, UK.
EurOtop (2007) European Manual for the Assessment of Wave Overtopping (Pullen T, Allsop NWH, Bruce T, Kortenhaus A, Schüttrumpf H and Van der Meer JW (eds)). EurOtop, Wallingford, UK. See http://www.overtoppingmanual.com (accessed 13/10/2018).

Ewans K, Bitner-Gregersen E and Soares CG (2006) Estimation of wind-sea and swell components in a bimodal sea state. Journal of Offshore Mechanics and Arctic Engineering 128(4): 265-270.

Garcia-Gabin W (2015) Wave bimodal spectrum based on swell and wind-sea components. IFAC-PapersOnLine 48(16): 223-228.

Goda Y (1985) Random Seas and Design of Maritime Structures, 2nd edn. World Scientific, Singapore.

Goda Y (2010) Random Seas and Design of Maritime Structures, 3rd edn. Advanced Series on Ocean Engineering. World Scientific, Singapore.

Hawkes PJ, Coates TT and Jones RJ (1998) Impact of Bi-Modal Seas on Beaches and Control Structures. Hydraulics Research, Wallingford, UK, Technical Report SR507.

Hayes MO, Michel J and Betenbaugh DV (2009) The intermittently exposed, coarse-grained gravel beaches of Prince William Sound, Alaska: comparison with open-ocean gravel beaches. Journal of Coastal Research 26(1): 4-30.

Horn D and Li L (2006) Measurement and modelling of gravel beach groundwater response to wave run-up: effects on beach profile changes. Journal of Coastal Research 22(5): $1241-1249$.

Horn DP (2002) Beach groundwater dynamics. Geomorphology 48(1-3): 121-146.

Horn DP and Walton SM (2007) Spatial and temporal variations of sediment size on a mixed sand and gravel beach. Sedimentary Geology 202(3): 509-528.

Hughes SA and Chiu TS (1981) Beach and Dune Erosion during Severe Storms. Coastal and Oceanographic Engineering Department, University of Florida, Gainesville, FL, USA, Technical Report No. TR/043.

Keulegan GH and Krumbein WC (1949) Stable configuration of bottom slope in shallow water and its bearing on geological processes. Transactions of the American Geophysical Union 30(6): 855-861.

Komar PD and Miller MC (1973) The threshold of sediment movement under oscillatory water waves. Journal of Sedimentary Petrology 43(4): 1101-1110.

Komar PD and Miller MC (1975) On the comparison between the threshold of sediment motion under waves and unidirectional currents with a discussion of the practical evaluation of the threshold. Journal of Sedimentary Petrology 45(1): 362-367.

López de San Román-Blanco BL (2001) Morphodynamics of Mixed Beaches. Unpublished transfer MPhil/PhD Report, Civil and Environmental Engineering Department, Imperial College, London, UK.

López de San Román-Blanco B, Coates T, Holmes P et al. (2006) Large scale experiments on gravel and mixed beaches: experimental procedure, data documentation and initial results. Coastal Engineering 53(4): 349-363.

Mackay E (2016) A unified model for unimodal and bimodal ocean wave spectra. International Journal of Marine Energy 15: $17-40$.

Mahalanobis PC (1930) On tests and measures of group divergence. Joumal of the Asiatic Society of Bengal 26: 541-588.

Mason T, Bradbury A, Poate T and Newman R (2008) Nearshore wave climate of the English Channel - evidence for bi-modal 
seas. Proceedings of 31st International Conference on Coastal Engineering. World Scientific, Singapore, pp. 605-616.

Masselink G, Castelle B, Scott T et al. (2016) Extreme wave activity during 2013/2014 winter and morphological impacts along the Atlantic coast of Europe. Geophysical Research Letters 43(5): 2135-2143.

McCall RT, Masselink G, Poate T et al. (2014) Modelling storm hydrodynamics on gravel beaches with XBeach-G. Coastal Engineering 91: 231-250.

Moses CA and Williams RB (2008) Artificial beach recharge: the south east England experience. Zeitschrift für Geomorphologie 52(3) 107-124.

Nicholls R (1990) Managing erosion problems on shingle beaches: examples from Britain. Proceeding of the 3rd European Workshop on Coastal Zones, Paralimni, Cyprus (Moutzouris C (ed.)).

Polidoro A, Pullen T and Powell K (2015) Modelling Shingle Beaches in Bimodal Seas, Test Methodologies \& Test Programme. HR Wallingford, Wallingford, UK, Technical Report CAS1217RT001-R03-00.

Powell KA (1990) Predicting Short Term Profile Response for Shingle Beaches. Hydraulics Research Limited, Wallingford, UK, Technical Report SR 219.
Powell KA (1993) Dissimilar Sediments: Model Tests of Replenished Beaches Using Widely Graded Sediments. HR Wallingford, UK, report SR 350 .

Smit P, Zijlema M and Stelling G (2013) Depth-induced wave breaking in a non-hydrostatic, near shore wave model. Coastal Engineering 76: $1-16$.

Thompson DA, Karunarathna $\mathrm{H}$ and Reeve DE (2017) Modelling extreme wave overtopping at Aberystwyth Promenade. Water 9(9): 663.

van der Meer JW (1988) Rock Slopes and Gravel Beaches under Wave Attack. PhD thesis, Delft University of Technology, Delft, the Netherlands.

Van Hijum E and Pilarczyk KW (1982) Equilibrium Profile and Longshore Transport of Coarse Material Under Regular and Irregular Wave Attack. Delft Hydraulics Laboratory, Delft, the Netherlands, Pub no. 274

Van Wellen E, Chadwick AJ and Mason T (2000) A review and assessment of longshore sediment transport equations for coarse grained beaches. Coastal Engineering 40(3): 243-275.

Yalin MS (1963) A model shingle beach with permeability and drag forces reproduced. Proceedings of the 10th IAHR congress, vol. 1, pp. $169-175$

\section{How can you contribute?}

To discuss this paper, please email up to 500 words to the editor at journals@ice.org.uk. Your contribution will be forwarded to the author(s) for a reply and, if considered appropriate by the editorial board, it will be published as discussion in a future issue of the journal.

Proceedings journals rely entirely on contributions from the civil engineering profession (and allied disciplines). Information about how to submit your paper online is available at www.icevirtuallibrary.com/page/authors, where you will also find detailed author guidelines. 